Article

\title{
Artificial Neural Network and Adaptive Neuro-Fuzzy Interface System Modelling to Predict Thermal Performances of Thermoelectric Generator for Waste Heat Recovery
}

\author{
Kunal Sandip Garud ${ }^{1}$, Jae-Hyeong Seo ${ }^{1}$ (D), Chong-Pyo Cho ${ }^{2}$ and Moo-Yeon Lee ${ }^{1, *(\mathbb{D})}$ \\ 1 School of Mechanical Engineering, Dong-A University, 37 Nakdong-Daero 550, Saha-gu, Busan 49315, Korea; \\ kunalgarud1@gmail.com (K.S.G.); cheonchw@naver.com (J.-H.S.) \\ 2 Energy Saving Technologies Laboratory, Korea Institute of Energy Research,152 Gajeong-ro, Yuseong-gu, \\ Daejeon 34129, Korea; cnsever@kier.re.kr \\ * Correspondence: mylee@dau.ac.kr; Tel.: +82-51-200-7659
}

Received: 16 January 2020; Accepted: 5 February 2020; Published: 8 February 2020

\begin{abstract}
The present study elaborates the suitability of the artificial neural network (ANN) and adaptive neuro-fuzzy interface system (ANFIS) to predict the thermal performances of the thermoelectric generator system for waste heat recovery. Six ANN models and seven ANFIS models are formulated by considering hot gas temperatures and voltage load conditions as the inputs to predict current, power, and thermal efficiency of the thermoelectric generator system for waste heat recovery. The ANN model with the back-propagation algorithm, the Levenberg-Marquardt variant, Tan-Sigmoidal transfer function and 25 number of hidden neurons is found to be an optimum model to accurately predict current, power and thermal efficiency. For current, power and thermal efficiency, the ANFIS model with pi-5 or gauss-5-membership function is recommended as the optimum model when the prediction accuracy is important while the ANFIS model with gbell-3-membership function is suggested as the optimum model when the prediction cost plays a crucial role along with the prediction accuracy. The proposed optimal ANN and ANFIS models present higher prediction accuracy than the coupled numerical approach.
\end{abstract}

Keywords: adaptive neuro-fuzzy interface system; artificial neural network; current; power; thermal efficiency; thermoelectric generator system; waste heat recovery

\section{Introduction}

In the last two decades, the researches on waste heat recovery technologies have been increased to diminish the global energy crisis [1]. The thermoelectric generators are the evolving technology for the waste heat recovery due to its non-polluting and silent operational characteristics [2]. The thermoelectric generators convert the thermal energy into the electricity using the Seebeck effect of semiconductor materials [2]. The automobile vehicles are the heavy consumers of the fossil fuel and approximately $30 \%-40 \%$ of heat is lost as the vehicle exhaust [3]. The significant research works have been done on the applications of the thermoelectric generators in the automobile vehicle for waste heat recovery. However, the low conversion efficiency of the thermoelectric generators restricts their commercialization in the automobile field [3]. To improve the performance of the thermoelectric generators in the waste heat recovery of the automobile vehicles, the hot heat exchanger is provided with various internal structures in the form of fins, inserts and protrusions.

Wang et al. have proved that the dimpled surface hot heat exchanger enhances the power output of the thermoelectric generator by $173.60 \%$ and reduces the pressure drop by $20.57 \%$ compared to 
inserted fins hot heat exchanger [3]. Niu et al. have recommended that the baffles should be installed in front of the thermoelectric modules and the baffle angle should be increased in the flow direction to enhance the performance of the thermoelectric generator and to reduce the pressure drop [4]. Liu et al. and Quan et al. have proved that the chaos shaped internal structure in the heat exchanger improves the power output and thermal performance of the automotive thermoelectric generators $[5,6]$. Luo et al. have improved the performance of the thermoelectric generators by proposing the heat exchanger with hotter side converges towards the inward [7]. Nithyanandam et al. have proposed that the metal foam-based heat exchanger shows 5.7 to 7.8 times higher power output than that without the metal foam for automobile waste heat recovery [8]. Cao et al. have proved that the heat pipe with insertion depth of $60 \mathrm{~mm}$ and gas flow direction of $15^{\circ}$ enhances the open circuit voltage, maximum power and maximum power density of the automotive thermoelectric generator system by 7.5, 10.17 and $15.49 \%$, respectively [9]. He et al. have shown that the plate type heat exchanger shows the maximum conversion efficiency of $5 \%$ for the louvered fins and $4.5 \%$ for the smooth and offset strip fins, respectively [10]. Lu et al. have proved that the hot heat exchanger configurations with uniform winglet vortex and non-uniform winglet vortex show higher power output of the thermoelectric generator than the hot heat exchanger without fins [11]. Rana et al. have the generated maximum power of $79.02 \mathrm{~W}$ by designing the heat exchanger with $0.08 \mathrm{~m}$ length, $1 \mathrm{~m}$ height, $4 \mathrm{~mm}$ gap size and 50 thermoelectric modules [12]. Suter et al. have proposed $1 \mathrm{~kW}$ thermoelectric stack with the counterflow parallel plate heat exchanger and 127 pairs of thermoelectric modules to convert the geothermal reservoir heat to electricity using the optimized stack volume of $0.0021 \mathrm{~m}^{3}$ and optimized the conversion efficiency of $4.2 \%$ [13]. Zhao et al. have showed that the application of intermediate fluid improves the maximum power output and generation efficiency of the automotive thermoelectric generator system $[14,15]$. Lu et al. have shown that 1-inlet 2-outlet heat exchanger has improved the performance characteristics compared to 2-inlet 2-outlet and empty cavity heat exchangers [16].

The conducted literature review concludes that the numerous experimental and numerical studies have been demonstrated on the thermoelectric generator system for waste heat recovery. The experimental study on the thermoelectric generator system for waste heat recovery shows that the energy imbalance results into the excessive loss within the system and improper insulation results in heat loss from the system to the environment. In addition, the thermocouples embedded into the thermoelectric generator system for waste heat recovery show measuring errors in the temperatures of various parts of the system, and manufacturing complexity arises due to non-uniform material properties. The numerical study on the thermoelectric generator system for waste heat recovery requires the powerful computational devices which involve higher computational time and higher computational cost. In the last few years, the artificial intelligence techniques have a secured position as the effective prediction tools to predict and optimize the performances of the various physical system. The artificial intelligence techniques are the most efficient tools to accurately predict the performance of the thermoelectric generator system for waste heat recovery and diminish the limitations of the corresponding experimental and numerical approaches. Dheenamma et al. have shown the artificial neural network models to predict the overall heat transfer coefficient, friction factors of hot and cold fluids, and effectiveness of the plate type heat exchanger by considering the Reynolds number of hot and cold fluids, Prandtl numbers of hot and cold fluids and the concentration of the cold fluid as the input conditions [17]. Angeline et al. have formulated the artificial neural network to predict the performance parameters of open circuit voltage, maximum power and matched load resistance of the thermoelectric generator for various hot side temperatures. The predicted results from the artificial neural network are found within 3\% error with the corresponding experimental results $[18,19]$.

The application of the artificial neural network and adaptive neuro-fuzzy interface system for the performance prediction of the thermoelectric generator system for waste heat recovery has not been investigated. Therefore, six ANN models with various combinations of training variants, transfer functions and the number of hidden neurons as well as seven ANFIS models with various combinations of types of membership functions and the number of membership functions are formulated. The developed ANN 
and ANFIS models predict the current, power and thermal efficiency of the thermoelectric generator system for waste heat recovery under the hot gas inlet temperatures and voltage load conditions.

\section{Experimental Set-Up}

The experimental set-up of the thermoelectric generator system for waste heat recovery is shown in Figure 1. The thermoelectric generator system for waste heat recovery is designed with heat exchanger, four cold fluid channels and 12 thermoelectric modules. The hot gas passes through the heat exchanger and the cold-water flows through the cold fluid channels. The thermoelectric modules are arranged between the heat exchanger body and the cold fluid channel to utilize the temperature difference between the hot gas and cold water. The thermoelectric modules convert the temperature difference of the hot gas and cold water into power using the Seebeck effect [20]. The heat exchanger and the cold fluid channels are constructed with aluminum material, whereas the thermoelectric modules are constructed with the skutterudite material. The heat exchanger is comprised of the frame with straight fins and guide fins in the inlet and outlet diffuser sections to enable the uniform distribution of the hot gas. The cold fluid channels are provided with the internal fins structure to enable the uniformity of water. Four cold fluid channels with two at the top of the heat exchanger and two at the bottom of the heat exchanger are arranged with three modules between each channel and heat exchanger. The thermoelectric generator system for waste heat recovery is installed in the airtight chamber filled with the argon gas at the pressure of $1 \times 10^{5} \mathrm{~Pa}$. The electric heater supplies the hot gas at the required temperature using the thermostat controller. The mass flow rate of the hot gas is measured by the mass flow indicator with an accuracy of $\pm 0.5 \%$ installed near the thermostat controller. The airtight vacuum chamber provides the constant temperature and pressure controlled by the chamber pressure regulator. In addition, the chamber pressure regulator indicates the inlet and outlet temperatures of the hot gas. The constant temperature chiller supplies the cold water to the cold fluid channels at the required temperature and pressure. The mass flow rate of the water is measured by the mass flow indicator with an accuracy of $\pm 0.5 \%$ installed on a tube which transfers the cold water from chiller to the cold fluid channels. The temperatures of the hot gas at the inlet and outlet of the heat exchanger, temperatures of the cold water at the inlet and outlet of the cold fluid channels, temperatures of the thermoelectric modules and the chamber are measured using nine K-type thermocouples with an accuracy $\pm 0.1{ }^{\circ} \mathrm{C}$. The thermocouples are connected to a KEYSIGHT 34970A data logger with an accuracy of $\pm 0.1 \%$ for monitoring the temperatures continuously. The thermoelectric modules are connected to the KIKUSUI PLZ334L electronic loader to record the current, voltage and power data with time. The accuracy of the electronic loader is $\pm 0.1 \%, \pm 0.2 \%$ and $\pm 0.6 \%$ for the current, voltage and power measurements, respectively.

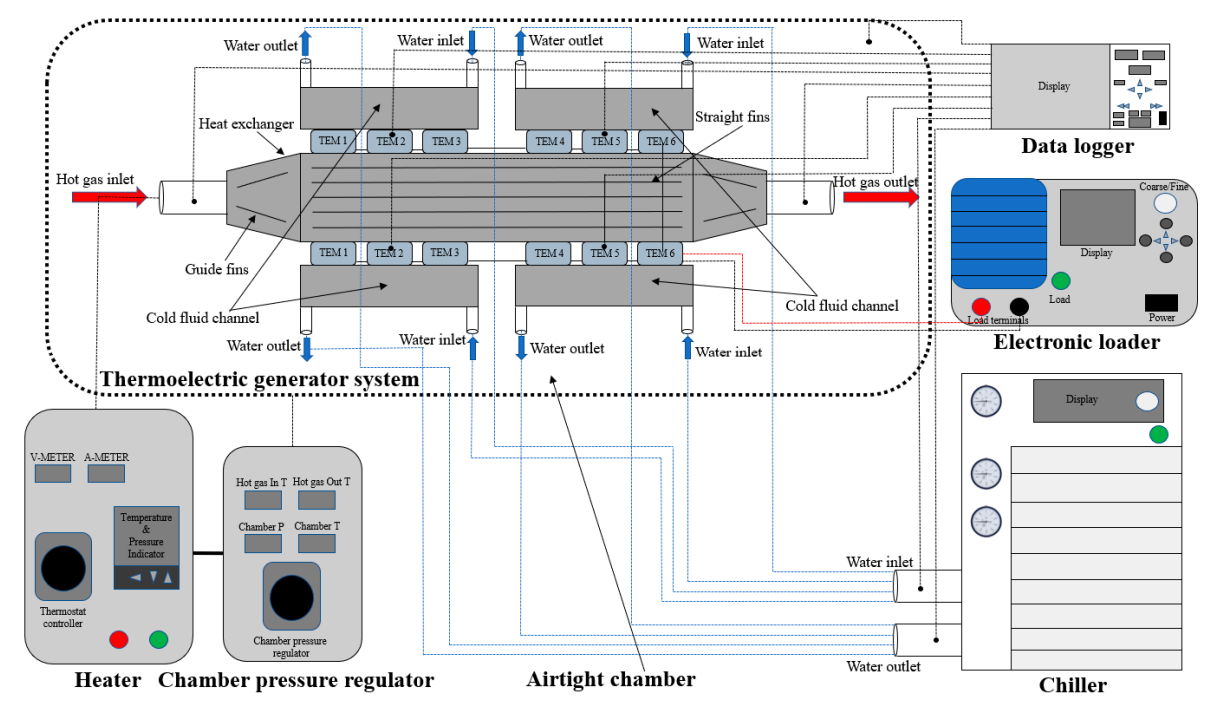

Figure 1. Experimental set-up of the thermoelectric generator system for waste heat recovery. 
The uncertainties of various measuring instruments and the measurement errors are considered in the experimental data. The temperature, mass flow rate, voltage, current, power and thermal efficiency are the experimentally predicted output data. Thus, uncertainties of the temperature, mass flow rate, voltage and current as the independent parameters are calculated with errors of the measuring instruments. The uncertainties of the power and thermal efficiency as the dependent parameters are calculated based on the linearized fraction approximation as shown by Equation (1) [21]. The uncertainties in the temperature, mass flow rate, voltage, current, power and thermal efficiency are showed as $\pm 0.24 \%, \pm 0.76 \%, \pm 1.27 \%, \pm 1.19 \%, \pm 1.74 \%$ and $\pm 1.91 \%$, respectively:

$$
w_{r}=\left[\left(\frac{\partial R}{\partial x_{1}} w_{1}\right)^{2}+\left(\frac{\partial R}{\partial x_{2}} w_{2}\right)^{2}+\cdots+\left(\frac{\partial R}{\partial x_{n}} w_{n}\right)^{2}\right]^{\frac{1}{2}}
$$

Here, $R$ is the dependent parameter, $w_{r}$ is the uncertainty in the dependent parameter, $x_{1}, x_{2}, \ldots x_{n}$ are the independent parameters and $w_{1}, w_{2}, \ldots w_{n}$ are the uncertainties in the independent parameters.

\section{Numerical Method}

The numerical analysis is conducted on the physical domain of the thermoelectric generator system for waste heat recovery. The physical domain of the thermoelectric generator system for waste heat recovery is comprised of the heat exchanger, cold fluid channels, thermoelectric modules and fluid domains of the hot gas and water. The coupled numerical approach comprises the CFX and the thermal electric solvers of ANSYS 19.1 commercial software is used to predict the current, power and thermal efficiency of the thermoelectric generator system for waste heat recovery [4]. The continuity, momentum, energy and thermoelectric coupling equations are solved using the coupled numerical approach. The boundary conditions for solving governing equations are shown in Table 1 . The experimental voltage conditions with time are used as the high potential voltage conditions for the numerical analysis. The low potential voltage is set to $0 \mathrm{~V}$ to ensure the flow of current from the high potential to the low potential of the thermoelectric module. The tetrahedrons mesh structure and fluid domains are used to solve the governing equations because of the complex geometrical structures of the thermoelectric generator system for waste heat recovery with the presence of fins and sharp corners. To verify the convergence of the predicted results, the grid dependency test is carried out for five different grid element numbers. Figure 2 shows the grid dependency test for the simulated power and thermal efficiency of the thermoelectric generator system for waste heat recovery. As shown in Figure 2, the simulated power and thermal efficiency values are converged within $\pm 1 \%$ above a grid element number of $11,431,310$. Therefore, considering the computational time and the computational cost, the grid element number of $11,431,310$ is selected as the final mesh configuration for the thermoelectric generator system for waste heat recovery to predict its current, power and thermal efficiency numerically. In numerical analysis, the density, specific heat, thermal conductivity and dynamic viscosity of the hot gas are set as $1.19 \mathrm{~kg} / \mathrm{m}^{3}, 1005 \mathrm{~J} / \mathrm{k} \cdot{ }^{\circ} \mathrm{C}, 0.026 \mathrm{~W} / \mathrm{m} \cdot \mathrm{K}$ and $1.8 \times 10^{-4} \mathrm{~kg} / \mathrm{m} \cdot \mathrm{s}$, respectively. The density, specific heat, thermal conductivity and dynamic viscosity of the water are set as $997 \mathrm{~kg} / \mathrm{m}^{3}, 4182 \mathrm{~J} / \mathrm{kg} \cdot{ }^{\circ} \mathrm{C}, 0.607 \mathrm{~W} / \mathrm{m} \cdot \mathrm{K}$ and $8.9 \times 10^{-4} \mathrm{~kg} / \mathrm{m} \cdot \mathrm{s}$, respectively. For skutterudite, the density, specific heat and thermal conductivity are used as $7598 \mathrm{~kg} / \mathrm{m}^{3}, 350 \mathrm{~J} / \mathrm{kg} \cdot{ }^{\circ} \mathrm{C}$ and $3.4 \mathrm{~W} / \mathrm{m} \cdot \mathrm{K}$, respectively. In addition, the Seebeck coefficient is set as $142.8 \mu \mathrm{V} / \mathrm{K}$ for $\mathrm{p}$-leg and $-183.5 \mu \mathrm{V} / \mathrm{K}$ for $\mathrm{n}-\mathrm{leg}$ [22]. The continuity, momentum and energy equations are expressed with Equations (2) to (5) [23].

Continuity Equation

$$
\frac{\partial \rho}{\partial t}+\nabla \cdot(\rho U)=0
$$

Momentum Equation

$$
\frac{\partial(\rho U)}{\partial t}+\nabla \cdot(\rho U \times U)=-\nabla p+\nabla \tau+S_{M}
$$


Stress tensor $\tau$ is expressed in terms of strain rate as follows:

$$
\tau=\mu\left(\nabla U+(\nabla U)^{T}-\frac{2}{3} \delta \nabla \cdot U\right)
$$

Energy equation

$$
\frac{\partial(\rho h)}{\partial t}+\nabla \cdot(\rho U h)=\nabla \cdot(\lambda \nabla T)+\tau: \nabla U+S_{E}
$$

where $\rho$ is the density $\left(\mathrm{kg} / \mathrm{m}^{3}\right), U$ is the average velocity $(\mathrm{m} / \mathrm{s}), \nabla$ is the nabla operator, $p$ is the static pressure (Pa), $\tau$ is the stress tensor, $S_{M}$ is the momentum source, $\mu$ is the dynamic viscosity (Pa.s), $h$ is the enthalpy $(\mathrm{J}), \lambda$ is the thermal conductivity $(\mathrm{W} / \mathrm{m} \cdot \mathrm{K})$ and $S_{E}$ is the energy source.

To deal with the turbulence of the hot gas and cold water, the k- $\varepsilon$ turbulence model [3] is used with Equations (6) and (7):

$$
\begin{gathered}
\frac{\partial\left(\rho u_{i} k\right)}{\partial x_{i}}=\frac{\partial}{\partial x_{i}}\left[\left(v+\frac{v_{t}}{\sigma_{k}}\right) \frac{\partial k}{\partial x_{i}}\right]+P_{k}-\rho \varepsilon \\
\frac{\partial\left(\rho u_{i} \varepsilon\right)}{\partial x_{i}}=\frac{\partial}{\partial x_{i}}\left[\left(v+\frac{v_{t}}{\sigma_{\varepsilon}}\right) \frac{\partial \varepsilon}{\partial x_{i}}\right]+\rho C_{1} S \varepsilon-\rho C_{2} \frac{\varepsilon^{2}}{k+\sqrt{v \varepsilon}}
\end{gathered}
$$

where $u_{i}$ is the velocity component, $k$ is the turbulence kinetic energy, $x_{i}$ is the cartesian co-ordinates, $v_{t}$ is the turbulent eddy viscosity, $\sigma_{k}$ is 1 based on reference [3], $\sigma_{\varepsilon}$ is 1.2 based on reference [3], $P_{k}$ is the shear production of the turbulent kinetic energy, $\varepsilon$ is the dissipation rate of the turbulence energy and $S$ is the modulus of the mean rate of the strain tensor.

The thermoelectric coupling equations [24] of Equations (8) and (9) are calculated:

$$
\begin{aligned}
& \nabla \cdot(p \cdot \vec{J})-\nabla \cdot(k \cdot \nabla T)=\vec{J} \cdot \vec{E} \\
& \nabla \cdot(\sigma \cdot \alpha \cdot \nabla T)+\nabla \cdot(\sigma \cdot \nabla \varnothing)=0
\end{aligned}
$$

where $p$ is the Peltier coefficient $(\mathrm{V}), \vec{J}$ is the electric current intensity $\left(\mathrm{A} / \mathrm{m}^{2}\right), k$ is the thermal conductivity $(\mathrm{W} / \mathrm{m} \cdot \mathrm{K}), \nabla T$ is the temperature gradient, $\vec{E}$ is the electric field intensity $(\mathrm{V} / \mathrm{m}), \sigma$ is the electrical conductivity $\left(\Omega^{-1} \cdot \mathrm{m}^{-1}\right), \alpha$ is the Seebeck coefficient $(\mathrm{V} / \mathrm{K})$, and $\nabla \varnothing$ is the electric potential $(\mathrm{J} / \mathrm{C})$.

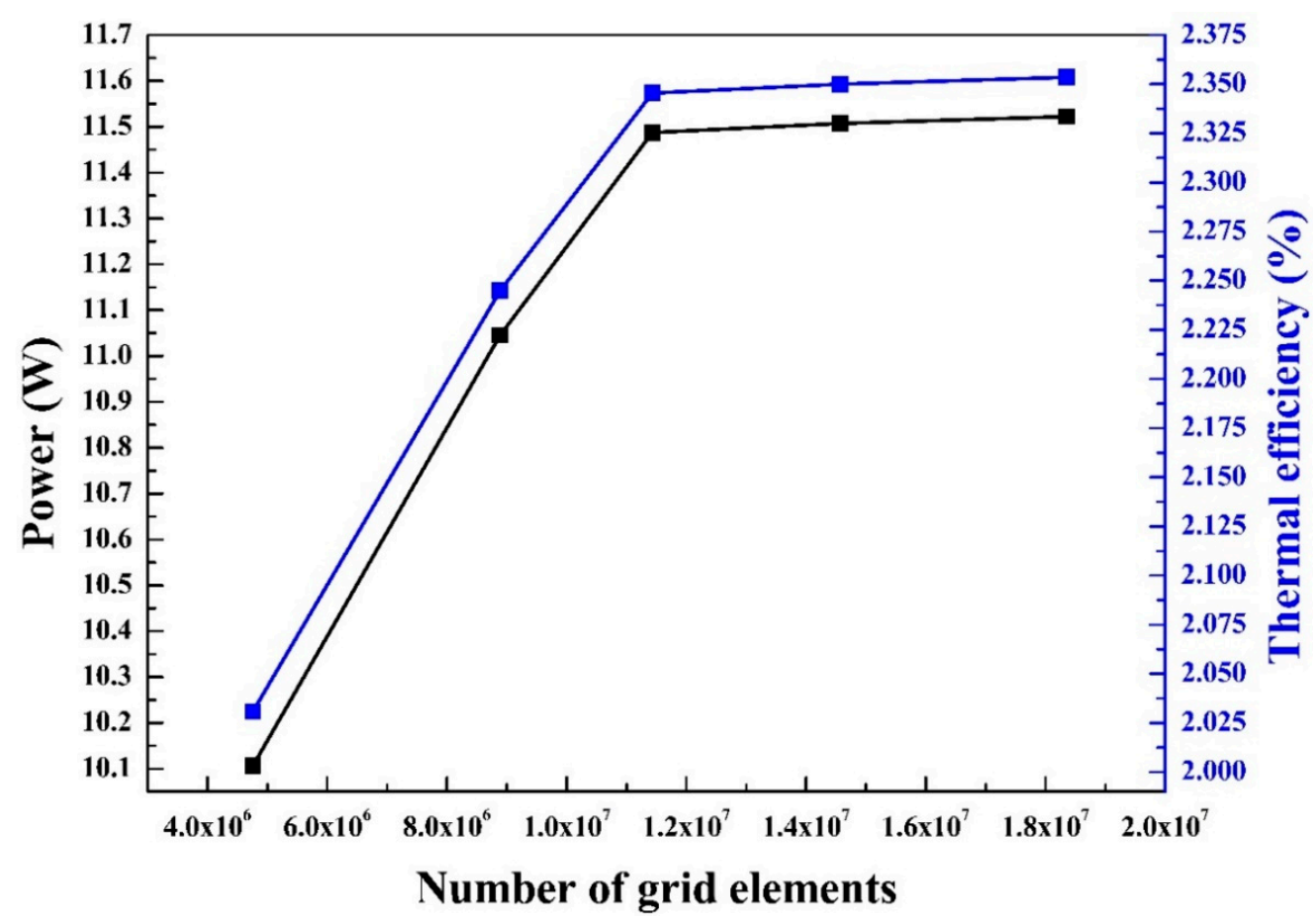

Figure 2. Grid dependency test for the simulated power and thermal efficiency. 
Table 1. Boundary conditions.

\begin{tabular}{cc}
\hline Parameter & Value \\
\hline Hot gas (air) inlet temperature $\left({ }^{\circ} \mathrm{C}\right)$ & $315.12,419.26,521.7,621.61$ \\
Coolant (water) inlet temperature $\left({ }^{\circ} \mathrm{C}\right)$ & 30 \\
Hot gas (air) mass flow rate $(\mathrm{kg} / \mathrm{s})$ & 0.018 \\
Coolant (water) mass flow rate $(\mathrm{kg} / \mathrm{s})$ & 0.075 \\
High potential voltage $(\mathrm{V})$ & 0 to $10 \mathrm{~V}$ \\
Low potential voltage $(\mathrm{V})$ & 0 \\
\hline
\end{tabular}

\section{Artificial Intelligence Models}

\subsection{Artificial Neural Network (ANN) Modelling}

The artificial neural network is the replica of the biological neural network which could be used for the optimization, simulation, modeling, forecasting and performance prediction of various physical systems [25]. The nonlinear relationship between the input and output variables with larger number of data points could be mapped efficiently using the ANN technique [25]. The ANN consists of three layers with the input layer, output layer and one or more than one hidden layer with a suitable number of neurons in each layer $[25,26]$. The number of neurons in the input layer is equal to the number of input parameters and number of neurons in the output layer is equal to number of output parameters. The number of hidden layers and hidden neurons are decided based on the training error [27]. The neurons of one layer are connected to the other layer using weights and the single weight value is assigned between two neurons [28]. The ANN structure with three layers and various numbers of neurons in each layer is trained using suitable training algorithm [29]. The training algorithm consists of the back-propagation algorithm, training variants and transfer functions [26]. For the training, the maximum training error and the maximum number of epochs are decided. During the training, the weight values get adjusted to predict the desired values of output parameters. If the error between the predicted output and the actual output is lower than the decided training error, the training is stopped; otherwise, further training is done to achieve the desired output [30]. The neural network structure with the desired prediction accuracy is selected as the optimum neural network structure.

In this study, six ANN models are developed to predict the performances of the thermoelectric generator system for waste heat recovery. Figure 3 shows the formulated ANN structure to predict the performance of thermoelectric generator system for waste heat recovery. The hot gas inlet temperature and voltage load conditions are considered as the inputs to the ANN models for predicting the current, power and thermal efficiency of the thermoelectric generator system for waste heat recovery. The back-propagation training algorithm is used to train the six ANN models. The six models are the combinations of three training variants of Levenberg-Marquardt (LM), Scaled Conjugate Gradient (SCG) and Pola-Ribiere Conjugate Gradient (CGP), and two transfer functions of Tan-Sigmoidal and Log-Sigmoidal and number of hidden neurons $(\mathrm{N})$ of 10, 15, 20, and 25. The maximum number of epochs is set to 1000 and the maximum training error is set to $10^{-6}$ for training to confirm the prediction accuracy of the tested model for the thermoelectric generator system for waste heat recovery. The experiments are conducted on the thermoelectric generator system for waste heat recovery at the hot gas inlet temperatures and voltage load conditions to collect the data for training. A total of 931 data points of the input and output parameters are used to train the six models. For each ANN model, the training is done until the error becomes steady and the outputs predicted by that trained model are recorded. The predicted output values of the current, power and thermal efficiency are compared with the corresponding experimental values based on three statistical parameters of the coefficient of determination $\left(\mathrm{R}^{2}\right)$, root mean square error (RMSE), and coefficient of variance (COV). The ANN model with the highest value of $R^{2}$ and the lowest values of RMSE and COV, respectively, is selected as the optimum ANN model to predict the current, power and thermal efficiency of the thermoelectric generator system for waste heat recovery for the hot gas inlet temperatures range of 315.12 to $621.61{ }^{\circ} \mathrm{C}$ and voltage load conditions range of 0 to $10 \mathrm{~V}$. 


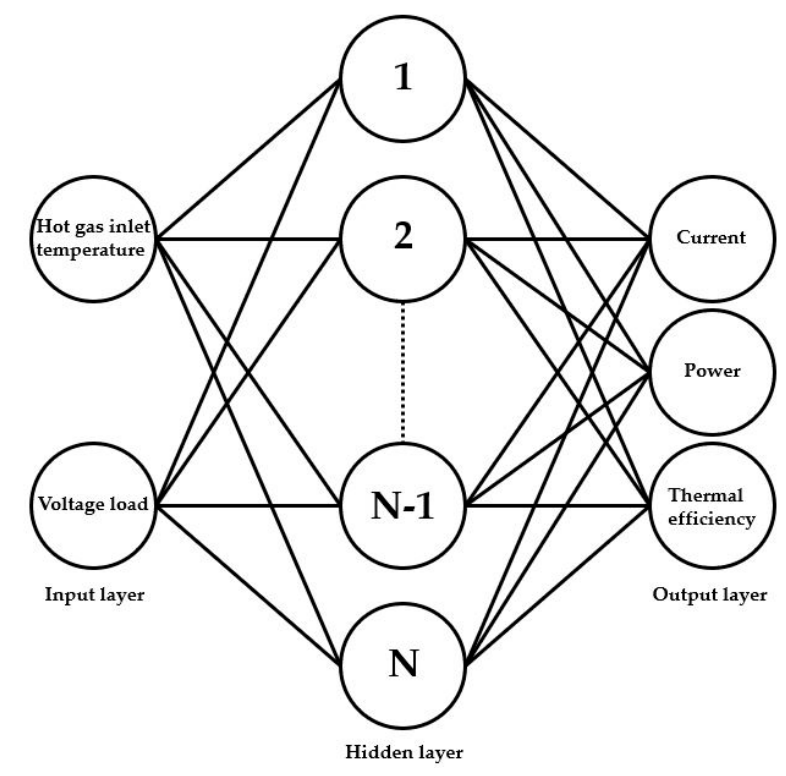

Figure 3. Formulated ANN structure to predict the performances of the thermoelectric generator system for waste heat recovery.

\subsection{Adaptive Neuro-Fuzzy Interface System Modelling (ANFIS)}

The ANFIS is one of the artificial intelligence techniques which is the combination of ANN and fuzzy logic [30]. The nonlinear relationship between the input and output parameters with a larger number of data points could be established accurately using ANFIS [30]. Like ANN, the ANFIS is also used to predict and optimize the performances of the various physical systems [31]. The input and output parameters needed to be related are imported in the ANFIS model in the form of neurons. The data of each input and output parameter are shown in the form of various membership functions [31]. The type of membership function and number of membership functions are decided based on the variation trend of the input and output data. The types of membership functions in the ANFIS model are triangular, trapezoidal, gbell, gauss, gauss2, pi, dsig and psig [32]. In the ANFIS model, the input and output data are connected by rules with the statements by showing the relationship between the input and output data. The prediction of the output values for the various input conditions are decided based on the rules. The ANFIS structure is trained using two algorithms of the back-propagation and hybrid [33]. The maximum number of epochs and maximum error are set for the training of an ANFIS model. During the training of ANFIS, the rules get adjusted to predict the desired output of the various physical systems like solar systems. The training is continued until the desired accuracy is achieved. The ANFIS model with the prediction value closest to the actual output is selected as the optimum model [33]. The output variables are predicted from the optimum ANFIS model by importing the input variables into the rule viewer [34].

Figure 4 shows the structure of formulated ANFIS model to predict the performance of the thermoelectric generator system for waste heat recovery. The selected ANFIS model type is a Takagi-Sugeno which has $n$ number of inputs with only one output prediction [35]. Hence, in the present ANFIS model, two input parameters of voltage and temperature are connected to one output parameter of current, power and thermal efficiency. Seven ANFIS models are formulated to predict the performances of the thermoelectric generator system for waste heat recovery and predict the current, power and thermal efficiency of the thermoelectric generator system for waste heat recovery with the hot gas temperatures and high potential voltage conditions. Seven membership functions of the triangular, trapezoidal, gauss, gauss2, gbell, pi and dsig are used to formulate the ANFIS models, and each ANFIS model is formulated with one type of the membership function. In each ANFIS model, each type of membership function is used with the number of sets of 2, 3, 4 and 5. The ANFIS models are trained for the same experimental data with sets of 931 data points used to train the ANN models. 
All ANFIS models are trained using the back-propagation algorithm for the maximum epochs of 1000 and maximum error of $10^{-6}$. The ANFIS models are trained until the training error becomes steady. Once the training error converges, the output values are predicted in the rule viewer by importing the input conditions of hot gas temperature and voltage conditions. The predicted values of the current, power and thermal efficiency by each ANFIS model are compared with the corresponding experimental values using three statistical parameters of $\mathrm{R}^{2}$, RMSE and COV. The ANFIS model with the optimum values of three statistical parameters is considered as the best model to predict the current, power and thermal efficiency of the thermoelectric generator system for waste heat recovery under the influence of various hot gas inlet temperatures and voltage conditions.

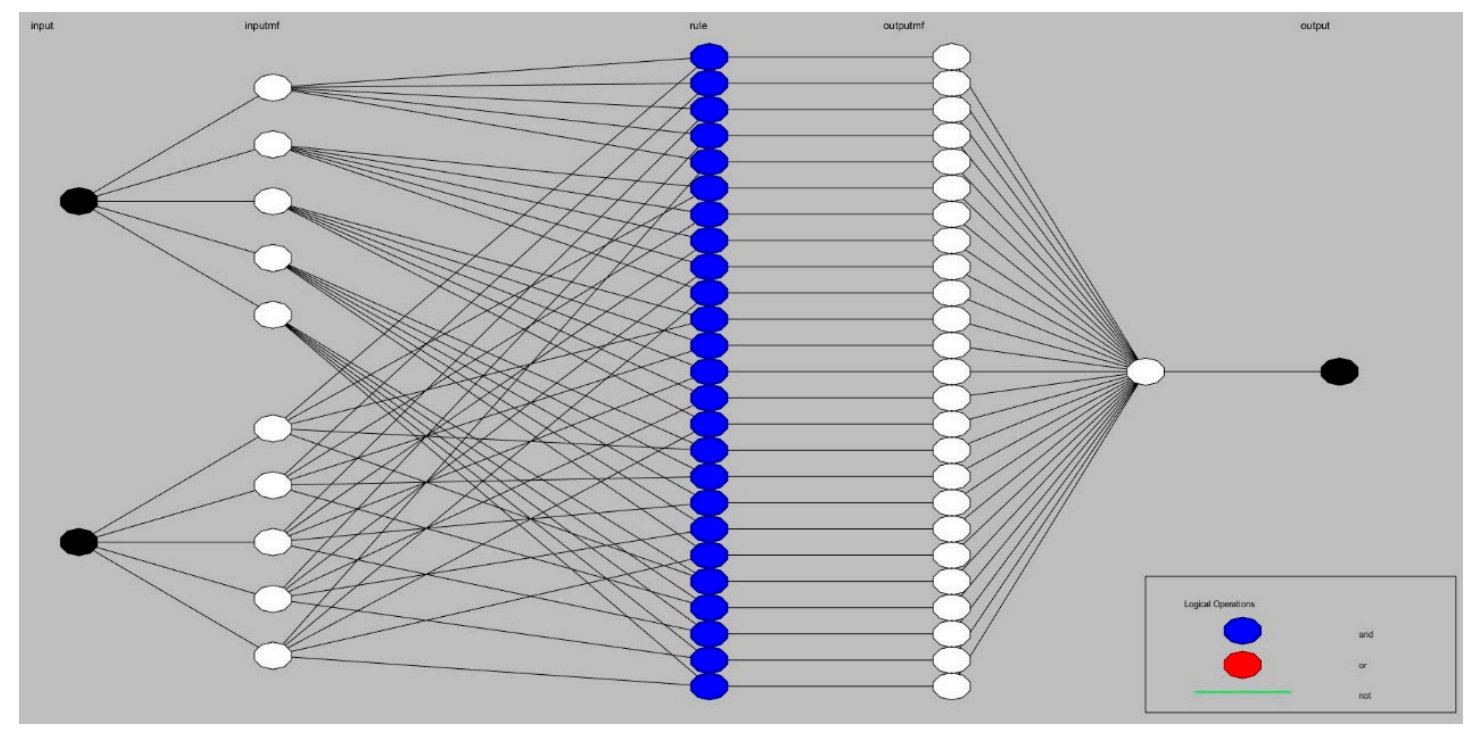

Figure 4. Formulated ANFIS model to predict the performances of the thermoelectric generator system for waste heat recovery.

\section{Data Reduction}

The power generated by the thermoelectric modules [36] is expressed with Equation (10):

$$
P=V I
$$

where $P$ is the power $(\mathrm{W})$ of the thermoelectric modules, $V$ is the voltage $(\mathrm{V})$ and $I$ is the current $(\mathrm{A})$.

The thermal efficiency of the thermoelectric generator system for waste heat recovery could be calculated with Equation (11) as the ratio of the power generated by the thermoelectric modules $(P)$ to the heat transfer through the thermoelectric modules ( $\dot{Q})$ [36]:

$$
\eta_{t h}=\frac{P}{\dot{Q}} \times 100 \%
$$

where $\eta_{t h}$ is the thermal efficiency (\%) of the thermoelectric generator system for waste heat recovery and $\dot{Q}$ is the heat transfer (W) through the thermoelectric modules. The heat transfer through the thermoelectric modules [37] is calculated using the Fourier's law of heat conduction as shown by Equation (12):

$$
\dot{Q}=\frac{K A}{t} \Delta T
$$

where $K$ is the thermal conductivity $(\mathrm{W} / \mathrm{m} \cdot \mathrm{K}), A$ is the surface area $\left(\mathrm{m}^{2}\right), t$ is the module thickness $(\mathrm{m})$ and $\Delta T$ is the temperature difference $\left({ }^{\circ} \mathrm{C}\right)$ of the thermoelectric module. 
The coefficient of determination $\left(R^{2}\right)$, root mean square error (RMSE) and coefficient of variance (COV) are calculated using Equations (13)-(15), respectively [38]:

$$
\begin{gathered}
R^{2}=1-\frac{\sum_{m=1}^{n}\left(X_{\text {pre }, m}-Y_{\text {mea }, m}\right)^{2}}{\sum_{m=1}^{n}\left(Y_{\text {mea }, m}\right)^{2}} \\
R M S E=\sqrt{\frac{\sum_{m=1}^{n}\left(X_{\text {pre }, m}-Y_{\text {mea }, m}\right)^{2}}{n}} \\
C O V=\frac{R M S E}{\left|\bar{Y}_{\text {mea }}\right|} \times 100
\end{gathered}
$$

where $R^{2}$ is the coefficient of determination, RMSE is the root mean square error, $C O V$ is the coefficient of variance, $n$ is the number of data points, $X_{\text {pre, } m}$ is predicted the value of the output parameter at data point $m, Y_{\text {mea, } m}$ is the experimental (actual) value of output parameter at data point $m$ and $\bar{Y}_{\text {mea }}$ is the average value at all experimental data points.

\section{Results and Discussion}

\subsection{Experimental Outputs of Current, Power and Thermal Efficiency}

The current, power and thermal efficiency as the performance parameters of the thermoelectric generator system for waste heat recovery are experimentally tested with the hot gas inlet temperatures of $315.12{ }^{\circ} \mathrm{C}, 419.26^{\circ} \mathrm{C}, 521.70{ }^{\circ} \mathrm{C}$ and $621.61{ }^{\circ} \mathrm{C}$ and the voltage load range of 0 to $10 \mathrm{~V}$. During the experiments, the voltage load is varied with time for each hot gas inlet temperature. Two experimental data sets for the development of a numerical method, ANN models and ANFIS models are considered as the training data set and testing data set of the thermoelectric generator system for waste heat recovery. The training data set (first) with variations of the current, power and thermal efficiency of thermoelectric generator system for waste heat recovery for hot gas inlet temperatures of $315.12{ }^{\circ} \mathrm{C}$, $419.26^{\circ} \mathrm{C}, 521.70{ }^{\circ} \mathrm{C}$ and $621.61^{\circ} \mathrm{C}$ and voltage load range of 0 to $10 \mathrm{~V}$ is selected and the testing data set (second) with the variation of current, power and thermal efficiency of thermoelectric generator system for waste heat recovery for hot gas inlet temperature of $419.26^{\circ} \mathrm{C}$ and voltage load range of 0 to $5.5 \mathrm{~V}$ is selected based on the experiments.

Figure 5 shows the variations of the current, power and thermal efficiency for the training and testing data sets. For all hot gas inlet temperatures, the current of the thermoelectric generator system for waste heat recovery is linearly decreased and the power and thermal efficiency of the thermoelectric generator system for waste heat recovery show the parabolic variations with the voltage load of range 0 to $10 \mathrm{~V}$ for the training data set and 0 to $5.5 \mathrm{~V}$ for the testing data set, respectively. The current, power and thermal efficiency of the thermoelectric generator system for waste heat recovery increase with the increase of the hot gas inlet temperature from $315.12{ }^{\circ} \mathrm{C}$ to $621.61{ }^{\circ} \mathrm{C}$. Therefore, the maximum and average values of the current, power and thermal efficiency of the thermoelectric generator system for waste heat recovery are increased with the increase of the hot gas inlet temperature. For the training data set, the maximum current of 4.1, 7.13, 9.42 and $10.95 \mathrm{~A}$ and average current of 2.28, 3.90, 4.99 and $5.95 \mathrm{~A}$, the maximum power of $3.40,9.75,17.55$ and $24.8 \mathrm{~W}$ and average power of $1.94,5.93,11.10$ and $15.22 \mathrm{~W}$ and the maximum efficiency of $1.28,2.16,2.87$ and $3.39 \%$ and average efficiency of $0.72,1.30$, 1.81 and $2.07 \%$ are selected experimentally at the hot gas inlet temperatures of $315.12{ }^{\circ} \mathrm{C}, 419.26^{\circ} \mathrm{C}$, $521.70{ }^{\circ} \mathrm{C}$ and $621.61{ }^{\circ} \mathrm{C}$, respectively. For the testing data set, the hot gas inlet temperature of $419.26^{\circ} \mathrm{C}$ is the same as the training data set, but the voltage load condition is different with time as shown in Figure 5. Thus, for the testing data set at the hot gas inlet temperatures of $419.26^{\circ} \mathrm{C}$, the maximum current is $8.1 \mathrm{~A}$ and the average current is $4.41 \mathrm{~A}$. The maximum power is $11.4 \mathrm{~W}$ and the average power is $6.95 \mathrm{~W}$. The maximum efficiency is $2.35 \%$ and the average efficiency is $1.43 \%$. As a result, the current, power and thermal efficiency of the thermoelectric generator system for waste heat recovery 
at the hot gas inlet temperature of $419.26^{\circ} \mathrm{C}$ are different for the training and testing data sets because of the different voltage loads.
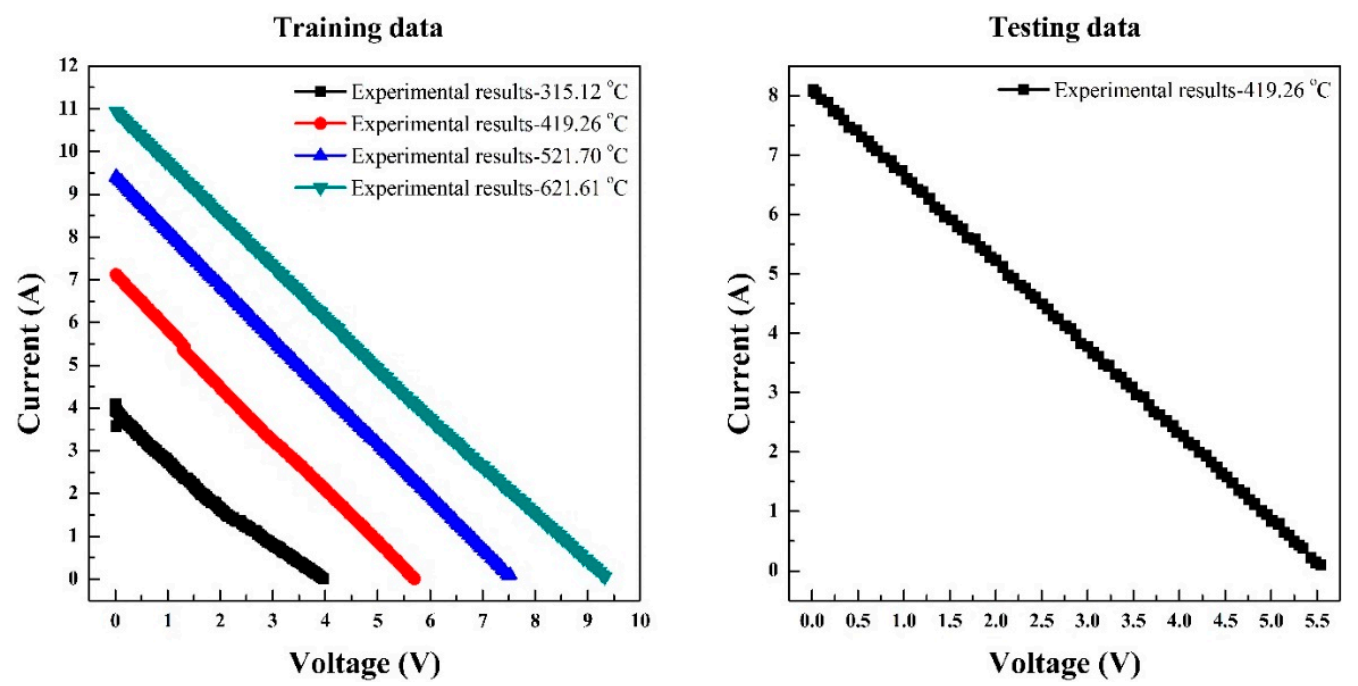

(a)
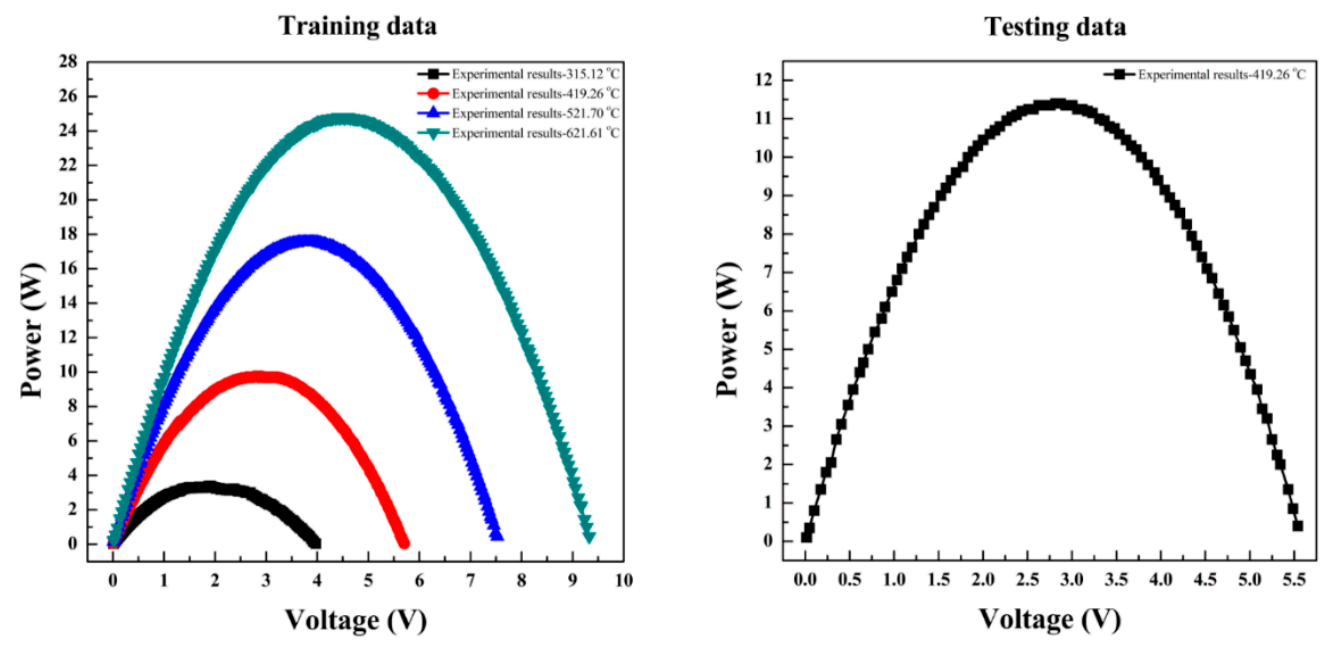

(b)
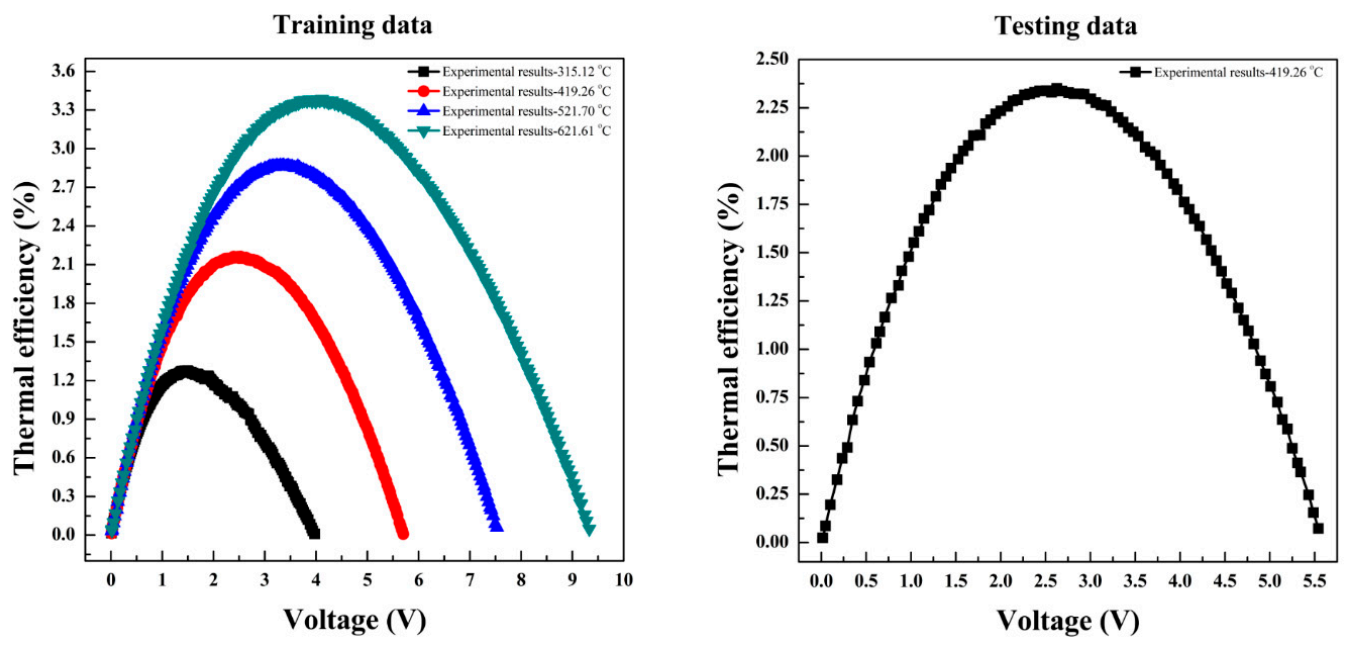

(c)

Figure 5. Variation of (a) current, (b) power, and (c) thermal efficiency for training and testing data sets. 


\subsection{Prediction Results from the Numerical Method}

The numerical simulation of the thermoelectric generator system for waste heat recovery at the hot gas inlet temperatures of $419.26^{\circ} \mathrm{C}$, cold water temperature of $30^{\circ} \mathrm{C}$, hot gas mass flow rate of $0.018 \mathrm{~kg} / \mathrm{s}$ and cold-water mass flow rate of $0.075 \mathrm{~kg} / \mathrm{s}$ is performed. From the numerical simulation of the thermoelectric generator system for waste heat recovery with various boundary conditions of the hot gas and cold water, the hot and cold surfaces of the thermoelectric modules are simulated.

The temperature of the hot gas decreases with the direction from the inlet to the outlet of the heat exchanger, but the temperature of the cold water increases as the cold water flows from the inlet to the outlet of the cold-water channel. This is because the hot gas transfers the heat and the cold water absorbs the heat from the thermoelectric modules. Therefore, the hot surface and cold surface temperatures of the thermoelectric module are varied with locations because the temperature distributions of the hot gas and cold water depend on the locations.

The temperature distributions of the hot and cold surfaces of the thermoelectric modules with locations ( $x$ and $y$ coordinates) at the hot gas inlet temperature of $419.26^{\circ} \mathrm{C}$ are showed in Figure 6 . Figure 6 shows the temperature distributions of the hot and cold surfaces of the top six thermoelectric modules and the corresponding bottom six thermoelectric modules. In addition, the hot surface temperatures of the thermoelectric module near the inlet of the heat exchanger show higher than those of the thermoelectric modules near the outlet of the heat exchanger. Thus, the current, power and thermal efficiency results of the thermoelectric generator system for waste heat recovery are simulated using the temperature distributions of the hot and cold surfaces of the thermoelectric modules and the voltage load conditions of the testing data set.

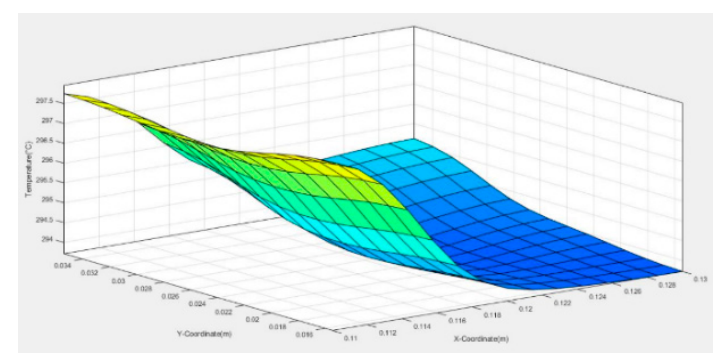

(a)

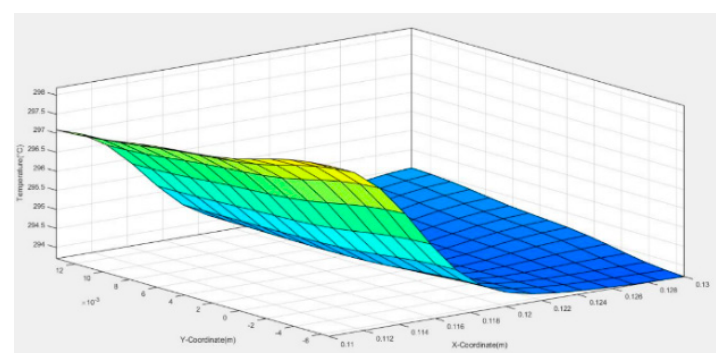

(c)

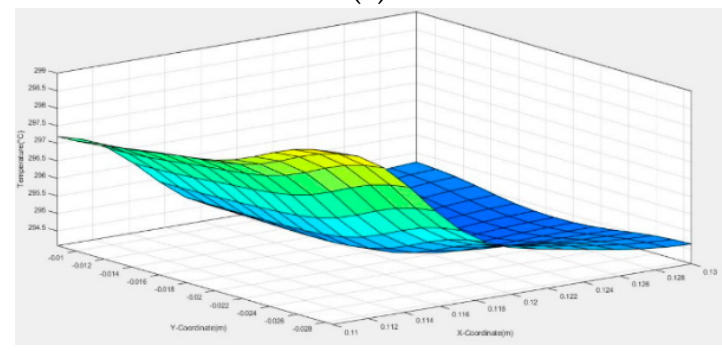

(e)

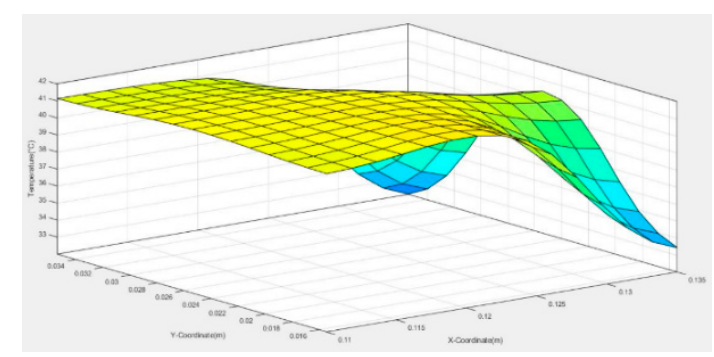

(b)

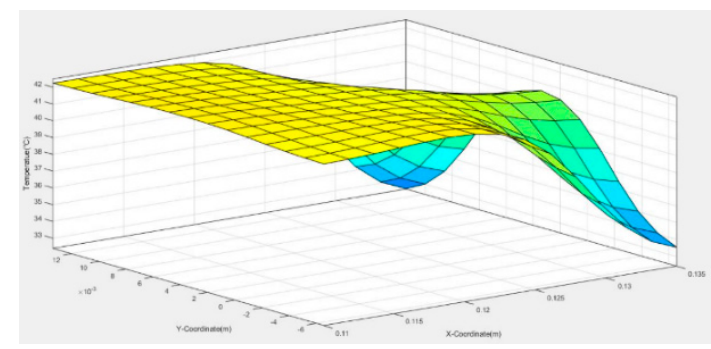

(d)

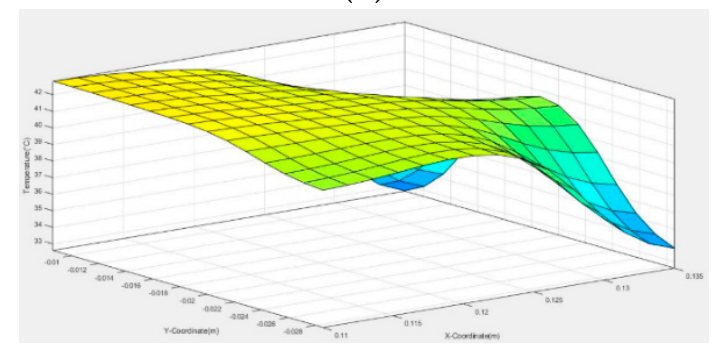

(f)

Figure 6. Cont. 


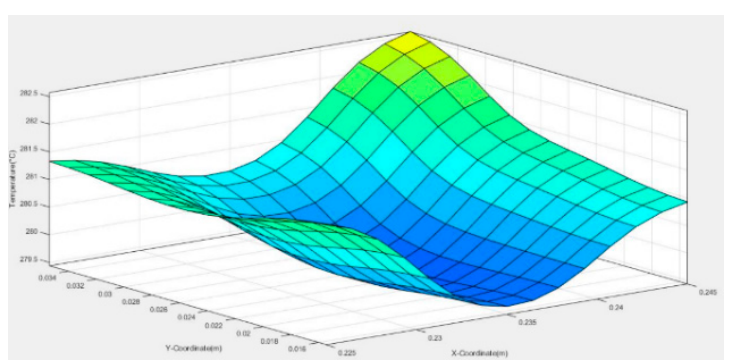

(g)

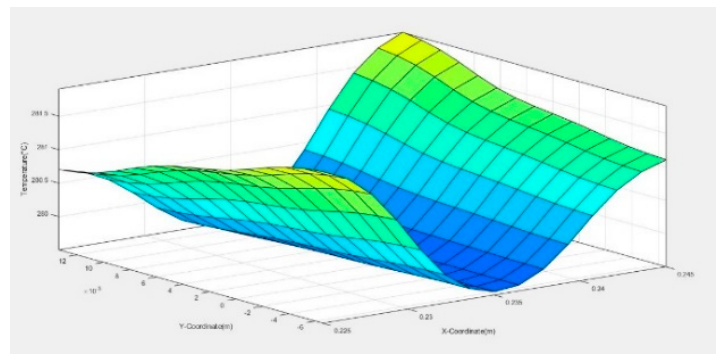

(i)

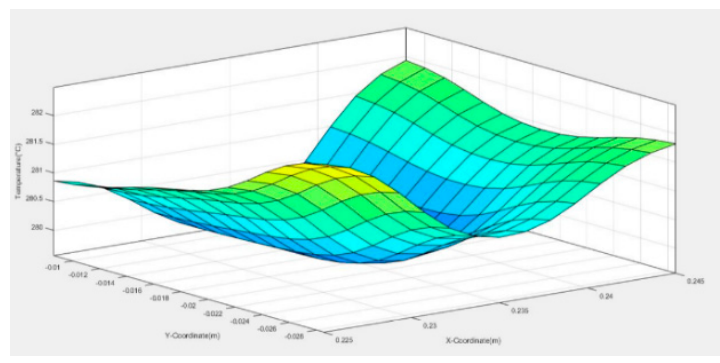

$(\mathbf{k})$

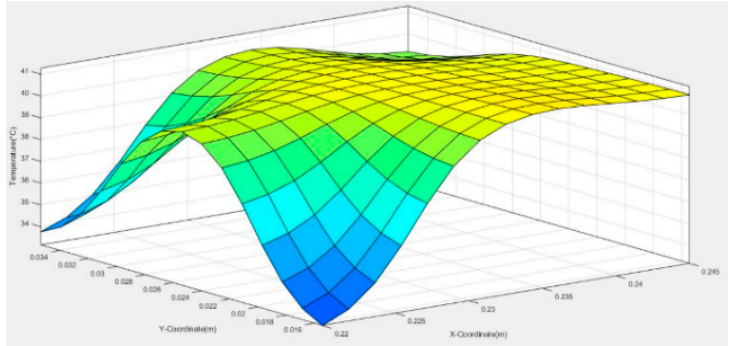

(h)

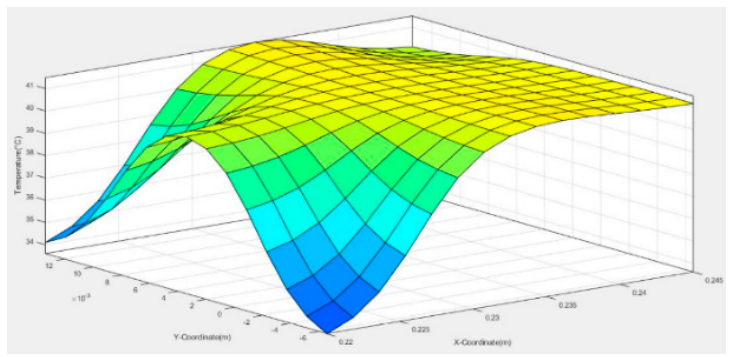

(j)

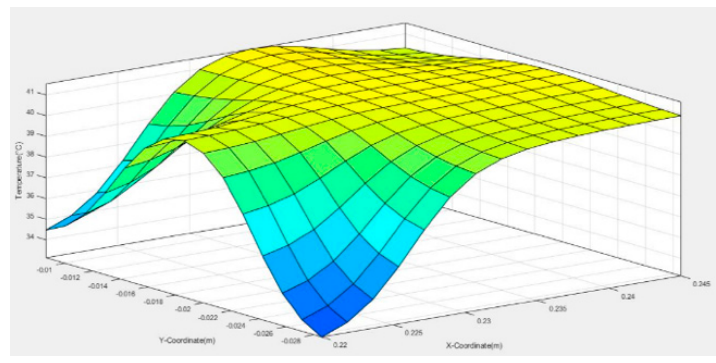

(1)

Figure 6. Temperature distributions (a) Module 1-hot surface, (b) Module 1-cold surface, (c) Module 2-hot surface, (d) Module 2-cold surface, (e) Module 3-hot surface, (f) Module 3-cold surface, (g) Module 4-hot surface, (h) Module 4-cold surface, (i) Module 5-hot surface, (j) Module 5-cold surface, (k) Module 6-hot surface, (l) Module 6-cold surface with locations ( $x$ and $y$ coordinates) at $419.26{ }^{\circ} \mathrm{C}$.

The comparisons of experimental and numerical results of the current, power and thermal efficiency of the thermoelectric generator system for waste heat recovery for the testing data set are shown in Figure 7. The error between the experimental and numerical values for the current of the thermoelectric generator system for waste heat recovery is validated within $2 \%$ except for the initial and end voltage conditions. In addition, the error between the experimental and numerical results for the power and thermal efficiency of the thermoelectric generator system for waste heat recovery is validated within $4 \%$ except for the initial and end voltage conditions.

The accuracy of numerical method for the current, power and thermal efficiency of the thermoelectric generator system for waste heat recovery is shown in Table 2. The numerical results of the current, power and thermal efficiency of the thermoelectric generator system for waste heat recovery show a good agreement with the corresponding experimental results [3]. The selection of the accurate boundary condition, meshing configuration with conduction and inflation effects, discretization method and suitable solver result in closer agreement between the numerical and experimental results of the thermoelectric generator system for waste heat recovery. Therefore, the experimental approach of the thermoelectric generator system for waste heat recovery with high manufacturing and installation costs, higher complexity and higher level of efforts could be replaced with a numerical approach of the thermoelectric generator system for waste heat recovery. 

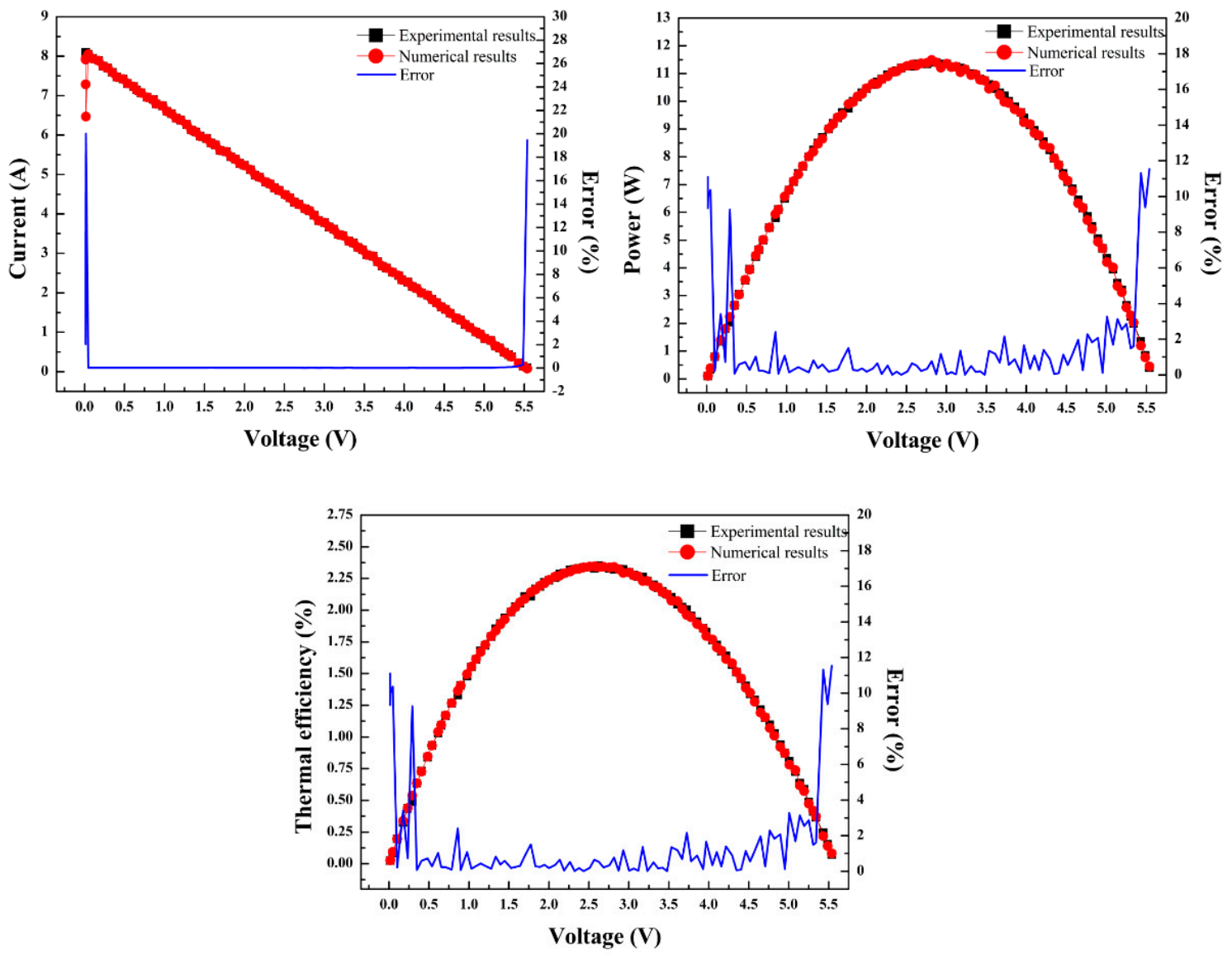

Figure 7. The comparisons of experimental and numerical results of the current, power and thermal efficiency for testing data set.

Table 2. The accuracy of numerical method for the current, power and thermal efficiency.

\begin{tabular}{cccc}
\hline Parameter & $\mathbf{R}^{\mathbf{2}}$ & RMSE & COV \\
\hline Current & 0.99865 & 0.18633 & 4.22614 \\
Power & 0.99992 & 0.07032 & 1.01243 \\
Thermal efficiency & 0.99992 & 0.01422 & 0.99102 \\
\hline
\end{tabular}

\subsection{Training and Testing Data Sets for ANN and ANFIS Models}

Figure 5 shows the training and testing data sets used to develop the ANN and ANFIS models of the thermoelectric generator system for waste heat recovery. Using these experimental data of both the hot gas inlet temperature and voltage condition as the input parameters and the current, power and thermal efficiency as the output parameters of the thermoelectric generator system for waste heat recovery, six ANN models and seven ANFIS models are formulated. As the training data set for training the ANN and ANFIS models of the thermoelectric generator system for waste heat recovery, a total of 931 data points of the mixtures of 225 data points at the hot gas inlet temperature of $315.12{ }^{\circ} \mathrm{C}, 234$ data points at the hot gas inlet temperature of $419.26{ }^{\circ} \mathrm{C}, 236$ data points at the hot gas inlet temperature of $521.70{ }^{\circ} \mathrm{C}$ and 236 data points at the hot gas inlet temperature of $621.61{ }^{\circ} \mathrm{C}$ are deducted from the experimental study. The training for the considered ANN and ANFIS models is stopped when the training error converges. The converged training errors for the considered ANN and ANFIS models are shown in Figure 8. To check the reliability and accuracy of the trained ANN and ANFIS models of the thermoelectric generator system for waste heat recovery, the additional experiment for obtaining the testing data set of 100 data is conducted at the hot gas inlet temperature of $419.26^{\circ} \mathrm{C}$ with the different voltage loads. 

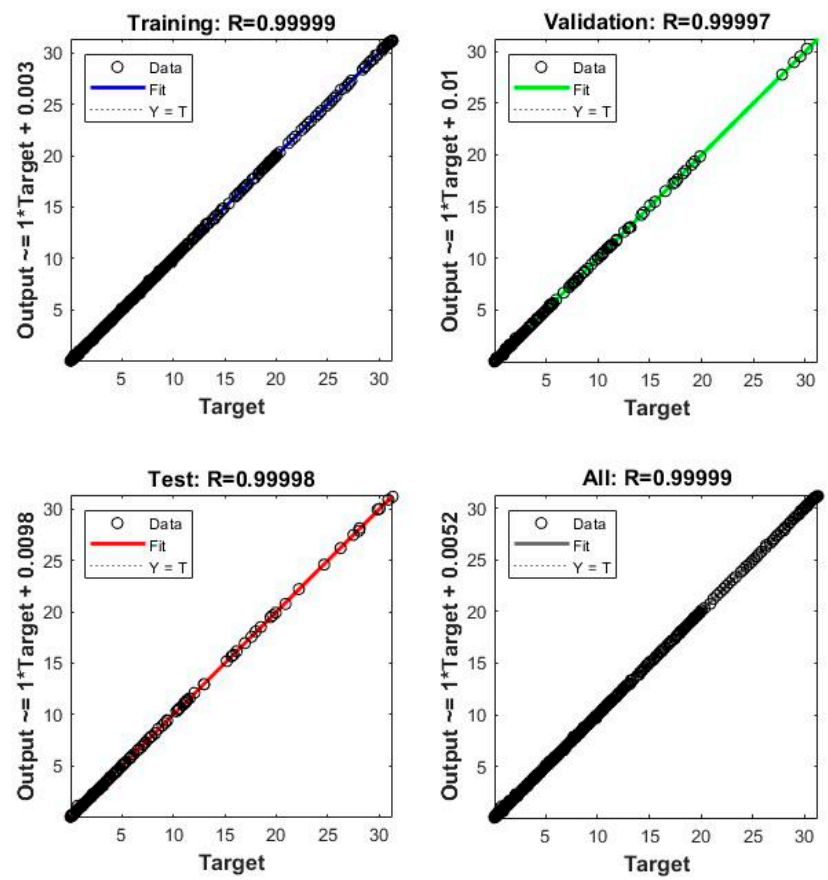

(a)

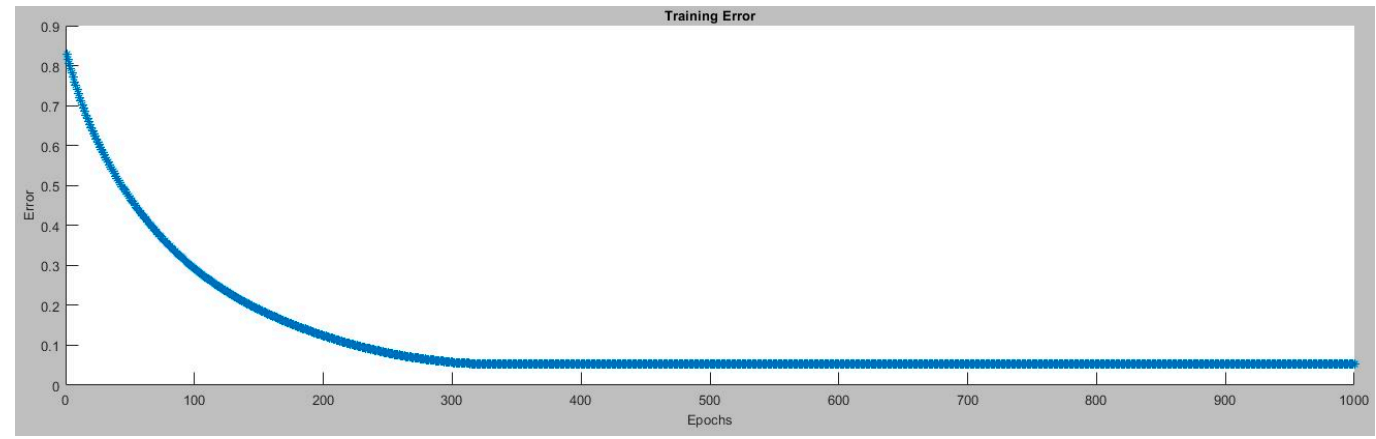

(b)

Figure 8. The converged training errors for (a) ANN and (b) ANFIS models of thermoelectric generator system for waste heat recovery.

The current, power and thermal efficiency of the thermoelectric generator system for waste heat recovery are predicted by ANN and ANFIS models for the hot gas inlet temperature of $419.26{ }^{\circ} \mathrm{C}$ and voltage loads of the testing data set. The predicted current, power and thermal efficiency of the thermoelectric generator system for waste heat recovery from the ANN and ANFIS models for the testing data set are compared with the corresponding experimental data of the testing data set. Based on the degree of closeness between the experimental and predicted results of the current, power and thermal efficiency of the thermoelectric generator system for waste heat recovery with ANN and ANFIS models, the optimum ANN and ANFIS models with higher prediction accuracy are decided.

\subsection{Prediction Results from ANN Models}

The comparison of experimental and ANN predicted results of the current, power and thermal efficiency of the thermoelectric generator system for waste heat recovery using an LM-TanSig algorithm with the various numbers of the hidden neurons is shown in Figure 9a. The increase of the hidden neurons number from 10 to 25 increases the prediction accuracy of the ANN model with an LM-TanSig algorithm. The values of $\mathrm{R}^{2}$, RMSE and COV of LM-TanSig algorithm with 25 hidden neurons are $0.99998,0.02163$ and 0.49061 , respectively for the current, $0.99997,0.04111$ and 0.59192 , respectively, for the power and $0.99996,0.01050$ and 0.73183 , respectively, for the thermal efficiency. 
The comparison of experimental and ANN predicted results of the current, power and thermal efficiency of the thermoelectric generator system for waste heat recovery using an LM-LogSig algorithm with the various numbers of the hidden neurons is shown in Figure 9b. The ANN model for the current and thermal efficiency of the thermoelectric generator system for waste heat recovery with LM-LogSig algorithm and 25 hidden neurons shows the peak prediction accuracy and this prediction accuracy decreases in an order with LM-LogSig algorithm of 20, 15 and 10 hidden neurons, respectively. The values of $\mathrm{R}^{2}$, RMSE and COV for LM-LogSig algorithm and 25 hidden neurons are 0.99998, 0.02370 and 0.53755 , respectively for the current and $0.99994,0.01225$ and 0.85347 , respectively for the thermal efficiency. For the power of the thermoelectric generator system for waste heat recovery, LM-LogSig algorithm with 20 hidden neurons shows higher prediction accuracy than that with 25, 15 and 10 hidden neurons, respectively. The values of $\mathrm{R}^{2}$, RMSE and COV for LM-LogSig algorithm with 20 hidden neurons are $0.99997,0.04632$ and 0.66686 , respectively for the power.

The comparison of experimental and ANN predicted results of the current, power and thermal efficiency of the thermoelectric generator system for waste heat recovery using SCG-TanSig algorithm with the various numbers of the hidden neurons is shown in Figure 9c. The ANN model for the current of the thermoelectric generator system for waste heat recovery with SCG-TanSig algorithm and 25 hidden neurons shows the peak prediction accuracy and this prediction accuracy decreases in an order with SCG-TanSig algorithm of 10, 25 and 15 hidden neurons, respectively. The values of $\mathrm{R}^{2}$, RMSE and COV for SCG-TanSig algorithm with 25 hidden neurons are 0.99992, 0.04524, 1.02613, respectively for the current of the thermoelectric generator system for waste heat recovery. The power and thermal efficiency of the thermoelectric generator system for waste heat recovery using the SCG-TanSig algorithm with 20 hidden neurons shows higher prediction accuracy than that with 10, 25 and 15 hidden neurons, respectively. The values of $\mathrm{R}^{2}$, RMSE and COV for SCG-TanSig algorithm with 20 hidden neurons are $0.99971,0.13652$ and 1.96554 , respectively, for the power and $0.99929,0.04377$ and 3.05105, respectively, for the thermal efficiency.

The comparison of experimental and ANN predicted results of the current, power and thermal efficiency of the thermoelectric generator system for waste heat recovery using an SCG-LogSig algorithm with the various numbers of the hidden neurons is shown in Figure 9d. The prediction accuracy for the current of the thermoelectric generator system for waste heat recovery with the SCG-LogSig algorithm decreases with 25, 15, 20 and 10 hidden neurons. The values of $\mathrm{R}^{2}$, RMSE and COV for SCG-LogSig algorithm with 25 hidden neurons are $0.99996,0.03138$ and 0.71178 , respectively, for the current. The prediction accuracy for the power of the thermoelectric generator system for waste heat recovery with SCG-LogSig algorithm decreases with 15, 10, 25 and 20 hidden neurons but prediction accuracy for the thermal efficiency of the thermoelectric generator system for waste heat recovery with SCG-LogSig algorithm decreases with 15, 25, 10 and 20 hidden neurons. The values of SCG-LogSig with 15 hidden neurons are $0.99980,0.11376$ and 1.63783 , respectively, for the power and $0.99958,0.03359$ and 2.34133, respectively, for the thermal efficiency.

The comparison of experimental and ANN predicted results of current, power and thermal efficiency of the thermoelectric generator system for waste heat recovery using the CGP-TanSig algorithm with various numbers of hidden neurons is shown in Figure 9e. The prediction accuracy of the thermoelectric generator system for waste heat recovery with the CGP-TanSig algorithm decreases with 20, 25, 10, and 15 hidden neurons for the current but 20,10,15 and 25 hidden neurons for the power, respectively. The values of $\mathrm{R}^{2}$, RMSE and COV for CGP-TanSig algorithm with 20 hidden neurons are 0.99989, 0.05377 and 1.21965 , respectively, for the current and $0.99945,0.18629$ and 2.68213 , respectively, for the power. In addition, the prediction accuracy for the thermal efficiency of the thermoelectric generator system for waste heat recovery using CGP-TanSig algorithm with 25 hidden neurons is the most accurate and decreases with 15, 20 and 10 hidden neurons, respectively. The values of CGP-TanSig algorithm with 25 hidden neurons are $0.99875,0.05805$ and 4.04596, respectively, for the thermal efficiency.

The comparison of experimental and ANN predicted results of current, power and thermal efficiency of the thermoelectric generator system for waste heat recovery using the CGP-LogSig 
algorithm with various numbers of hidden neurons is shown in Figure 9f. The CGP-LogSig algorithm with 25 hidden neurons predicts current values of the thermoelectric generator system for waste heat recovery closer to the corresponding experimental current values of the thermoelectric generator system for waste heat recovery with $\mathrm{R}^{2}$, RMSE and COV values of $0.99989,0.05354$ and 1.21437, respectively. The CGP-LogSig algorithm with 20,15, and 10 hidden neurons shows the decreasing order of prediction accuracy for the current of the thermoelectric generator system for waste heat recovery. The CGP-LogSig algorithm with 15, 20, 25 and 10 hidden neurons, respectively, shows the decreasing order of prediction accuracy for the power of the thermoelectric generator system for waste heat recovery and CGP-LogSig algorithm with 15, 25, 10 and 20 hidden neurons, respectively, shows the decreasing order of prediction accuracy for the thermal efficiency of the thermoelectric generator system for waste heat recovery. The $\mathrm{R}^{2}$, RMSE and COV values for CGP-LogSig algorithm with 15 hidden neurons are $0.99953,0.17188$ and 2.47463 , respectively, for power and $0.99848,0.06391$ and 4.45470, respectively, for the thermal efficiency.

The comparison of ANN models with various combinations of the training variants, transfer functions and number of the hidden neurons is shown. The combination of LM training variant with TanSig and LogSig transfer functions and all numbers of the hidden neurons show better accuracy than that of SCG and CGP training variants with TanSig and LogSig transfer functions and all numbers of hidden neurons to predict current, power and thermal efficiency of the thermoelectric generator system for waste heat recovery. In particular, the ANN model with LM-TanSig training algorithm and 25 hidden neurons shows the best prediction accuracy $[29,39]$ and is suggested as the optimum model for predicting the current, power and thermal efficiency of the thermoelectric generator system for waste heat recovery for the hot gas temperature ranges of 315.12 to $621.61{ }^{\circ} \mathrm{C}$ and voltage load ranges of 0 to $10 \mathrm{~V}$. The accuracy of the current, power and thermal efficiency of the thermoelectric generator system for waste heat recovery using the ANN model with the LM-TanSig algorithm and 25 hidden neurons are 0.99998 , 0.99997 and 0.99996 , respectively, as shown in Table 3. Table 3 shows the prediction accuracy of the optimum ANN model with the LM-TanSig algorithm and various numbers of the hidden neurons for the current, power and thermal efficiency of the thermoelectric generator system for waste heat recovery.
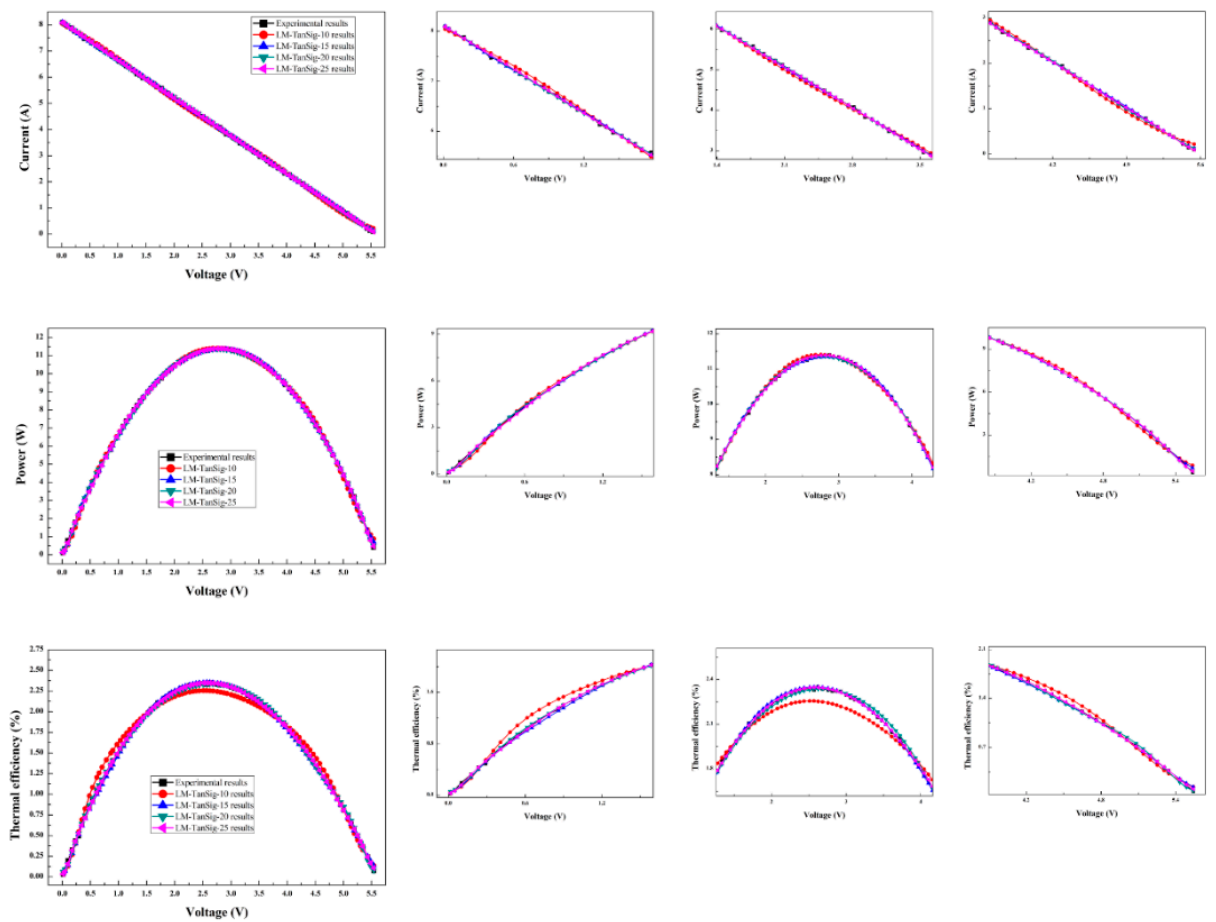

(a)

Figure 9. Cont. 

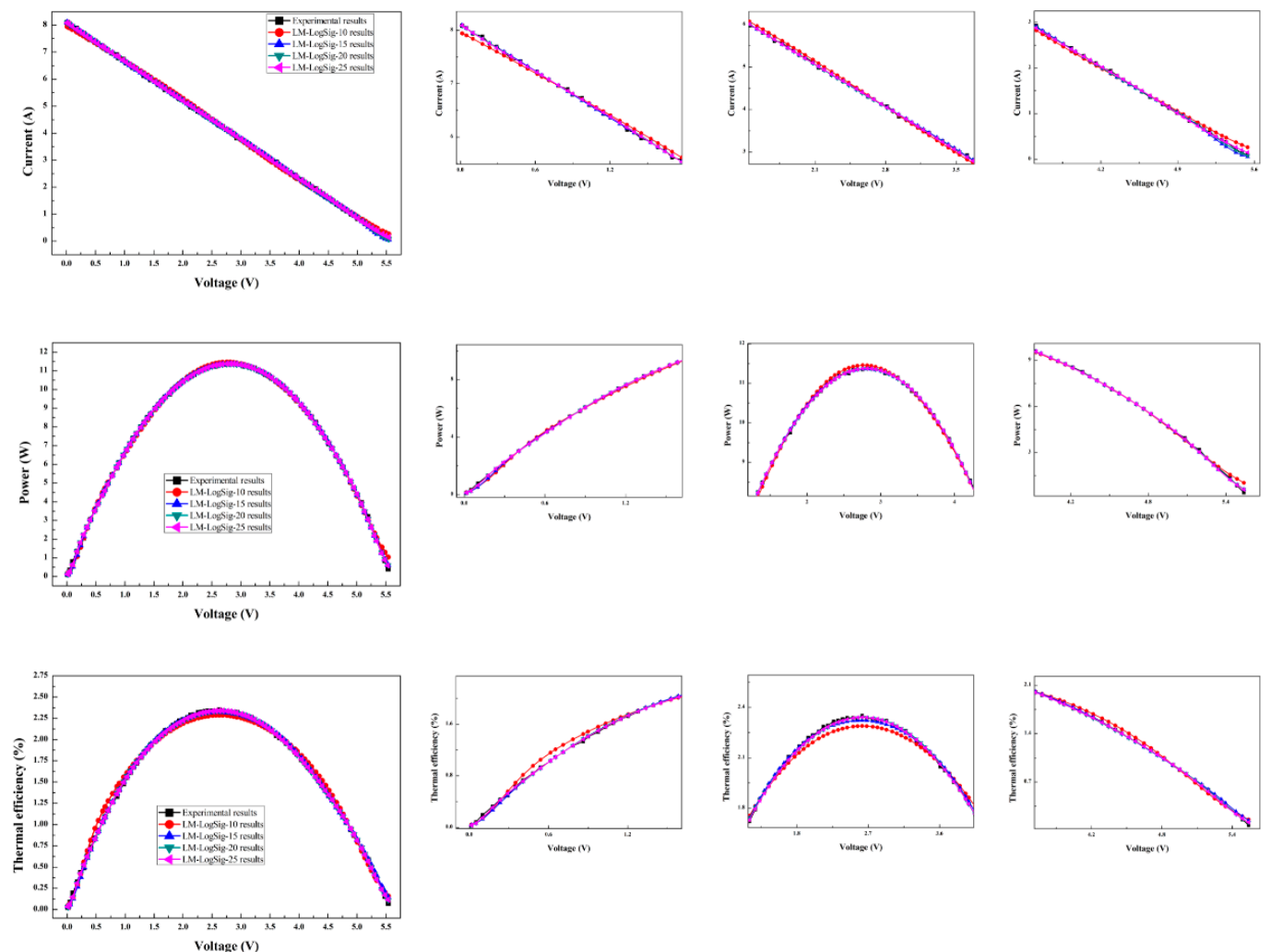

(b)
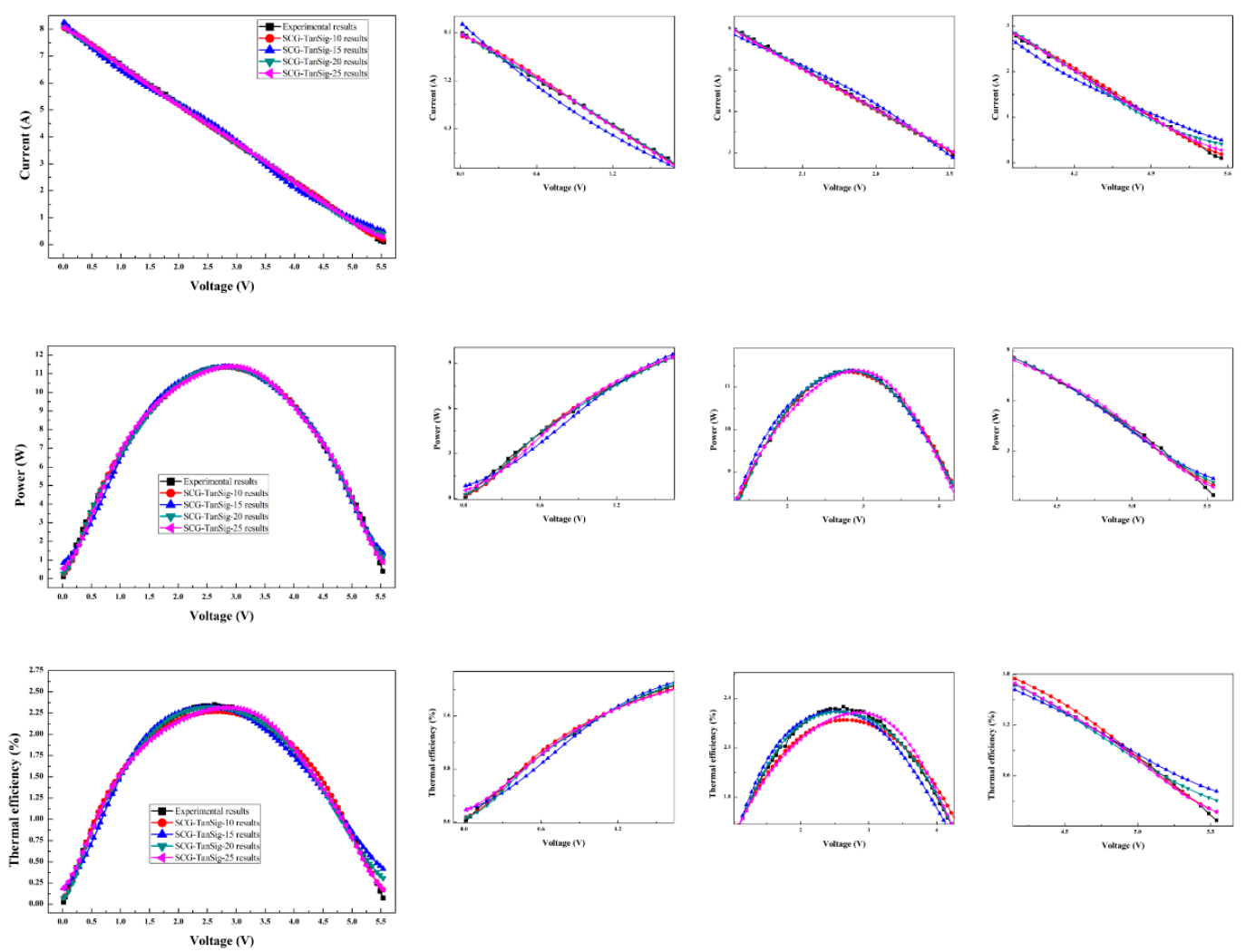

(c)

Figure 9. Cont. 

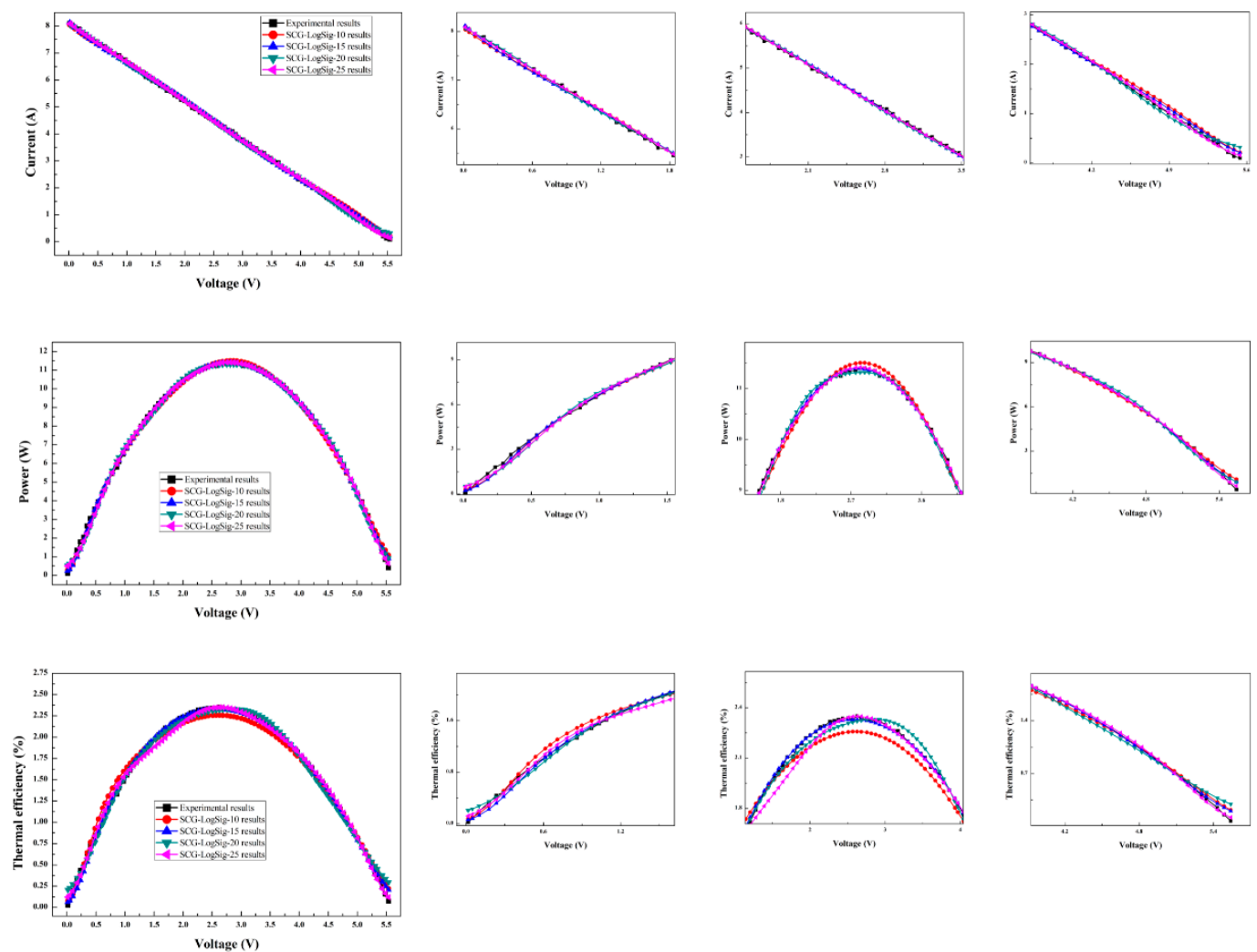

(d)
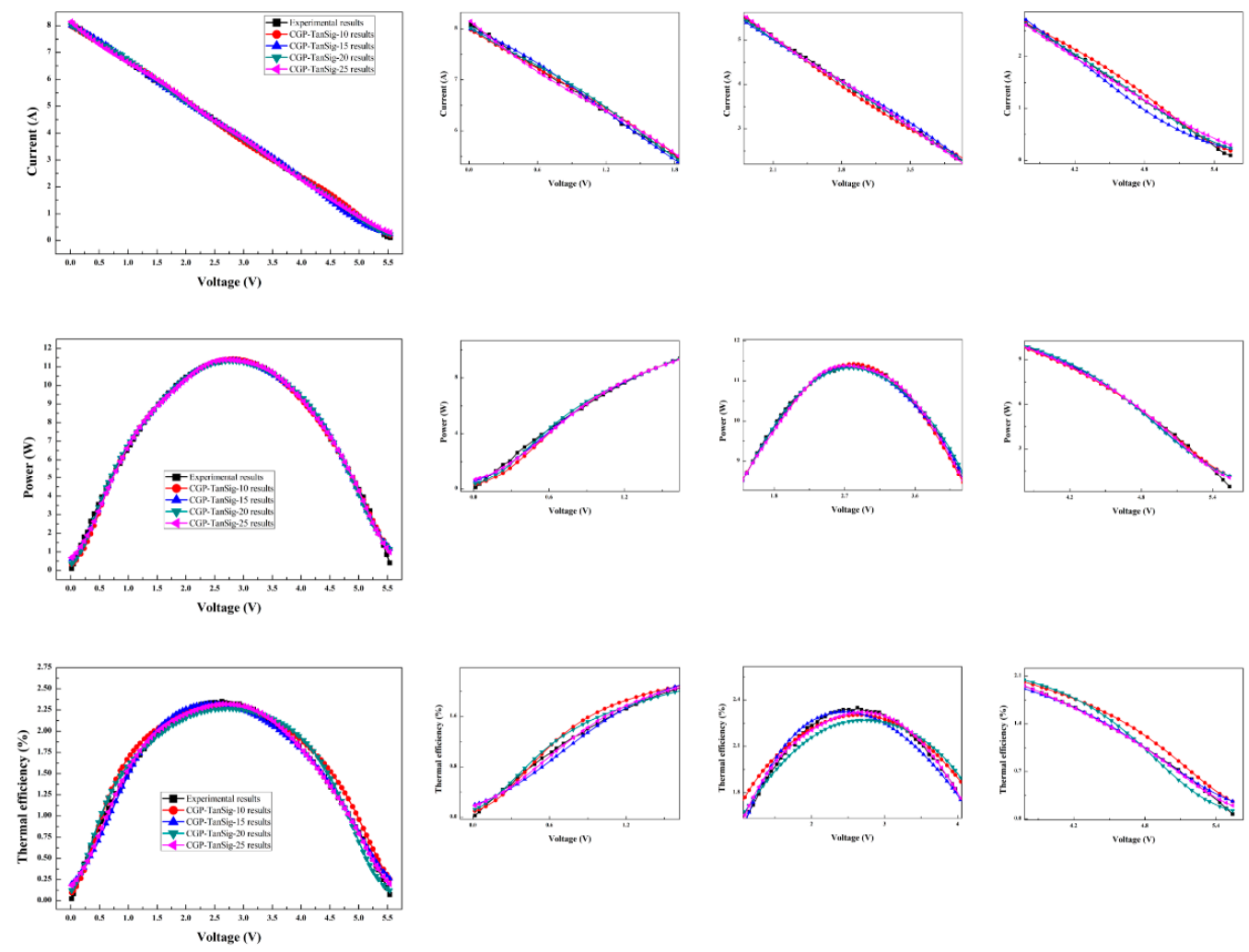

(e)

Figure 9. Cont. 

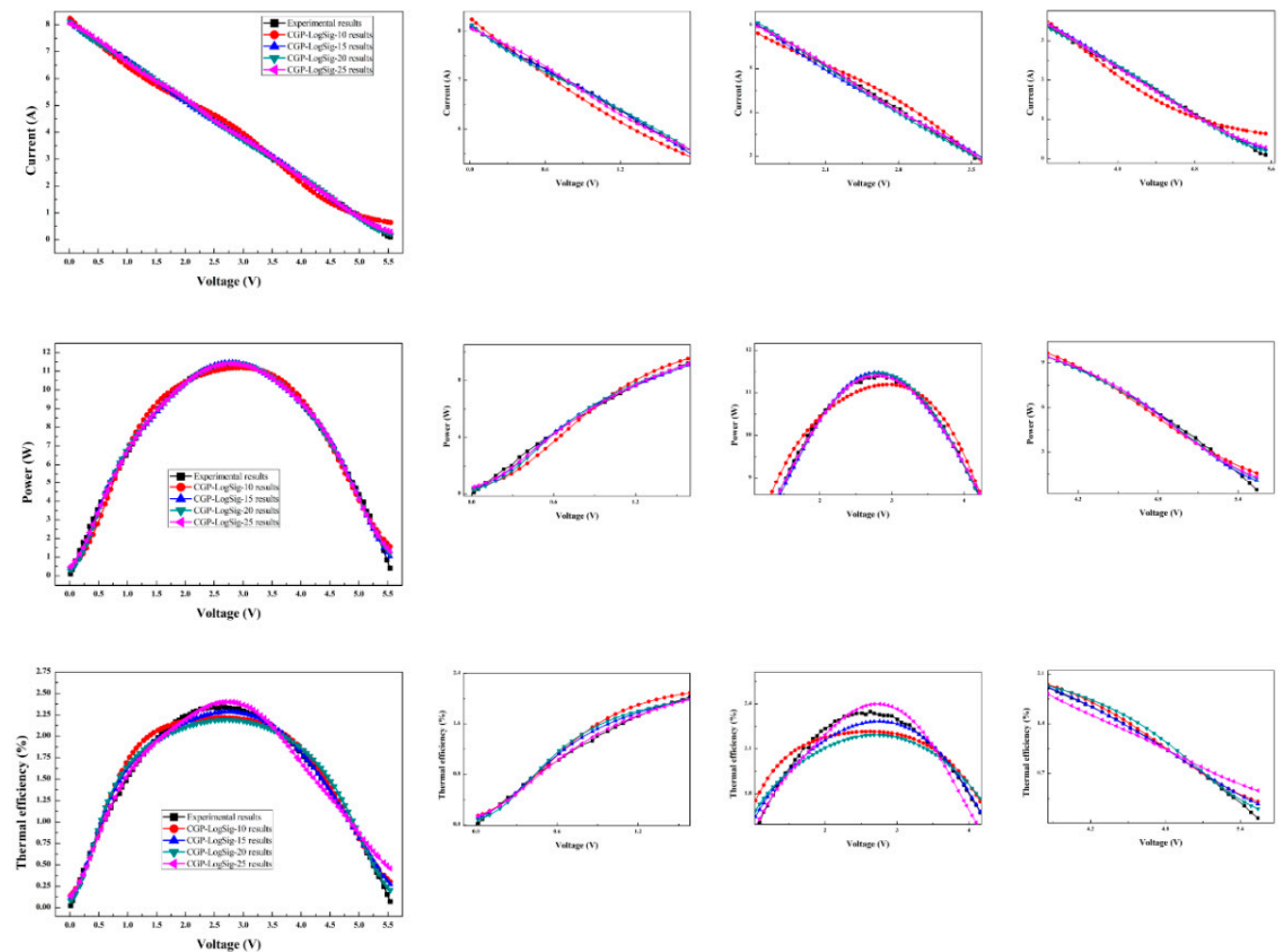

(f)

Figure 9. The comparison of experimental and ANN predicted results of current, power and thermal efficiency for (a) LM-TanSig algorithm, (b) LM-LogSig algorithm, (c) SCG-TanSig algorithm, (d) SCG-LogSig algorithm, (e) CGP-TanSig algorithm, and (f) the CGP-LogSig algorithm with various numbers of hidden neurons.

Table 3. The prediction accuracy of optimum ANN model with LM-TanSig algorithm and various numbers of hidden neurons for current, power and thermal efficiency.

\begin{tabular}{ccccc}
\hline Parameter & Number of Hidden Neurons & $\mathbf{R}^{\mathbf{2}}$ & $\mathbf{R M S E}$ & $\mathbf{C O V}$ \\
\hline Current & 10 & 0.99986 & 0.06013 & 1.36373 \\
& 15 & 0.99997 & 0.02578 & 0.58476 \\
20 & 0.99998 & 0.02507 & 0.56860 \\
& 25 & 0.99998 & 0.02163 & 0.49061 \\
\hline Power & 10 & 0.99977 & 0.12180 & 1.75370 \\
& 15 & 0.99993 & 0.06769 & 0.97459 \\
& 20 & 0.99993 & 0.06609 & 0.95152 \\
Thermal efficiency & 25 & 0.99997 & 0.04111 & 0.59192 \\
& 10 & 0.99809 & 0.07170 & 4.99773 \\
& 15 & 0.99983 & 0.02126 & 1.48165 \\
& 20 & 0.99981 & 0.02277 & 1.58688 \\
& 25 & 0.99996 & 0.01050 & 0.73183 \\
\hline
\end{tabular}

\subsection{Prediction Results from ANFIS Models}

The comparison of experimental and ANFIS predicted results of the current, power and thermal efficiency of the thermoelectric generator system for waste heat recovery using the triangular membership function is shown in Figure 10a. The triangular with 4-membership function shows higher prediction accuracy with $\mathrm{R}^{2}$, RMSE and COV of 0.99998, 0.02209 and 0.50106, respectively and the prediction accuracy decreases in order of triangular with 5-, 2- and 3-membership functions for the current of the thermoelectric generator system for waste heat recovery. For the power of the 
thermoelectric generator system for waste heat recovery, the triangular with 4-membership function shows a good agreement with the experimental results with $\mathrm{R}^{2}$, RMSE and COV of $0.99973,0.13024$ and 1.87522 , respectively. The prediction accuracy of the triangular with 5- and 3-membership functions shows a good agreement within $\pm 5 \%$, but the prediction accuracy of the triangular with 2-membership function shows over $\pm 15 \%$ from the corresponding experimental which are not a permissible limit. In the case of the thermal efficiency of the thermoelectric generator system for waste heat recovery using the triangular with 4-membership function shows the peak prediction accuracy and this prediction accuracy decreases in an order with the triangular with 5- and 3-membership functions. The values of $\mathrm{R}^{2}$, RMSE and COV for the thermal efficiency of the thermoelectric generator system for waste heat recovery using the triangular with 4-membership function are 0.99968, 0.02955 and 2.05980, respectively. The thermal efficiency of the thermoelectric generator system for waste heat recovery using the triangular with a 2-membership function shows the errors over $\pm 15 \%$ from the corresponding experimental thermal efficiency as shown in Figure 10a.

The comparison of experimental and ANFIS predicted results of the current, power and thermal efficiency of the thermoelectric generator system for waste heat recovery using trapezoidal membership function is shown in Figure 10b. The prediction accuracy for the current and power of the thermoelectric generator system for waste heat recovery using the trapezoidal with 5-membership function shows the best. The values of $\mathrm{R}^{2}$, RMSE and COV for the trapezoidal with 5-membership function are 0.99998 , 0.02333 and 0.52922 , respectively, for the current and $0.99982,0.10528$ and 1.51577 , respectively, for the power. In the case of the thermal efficiency of the thermoelectric generator system for waste heat recovery, the trapezoidal with a 4-membership function shows higher prediction accuracy than the trapezoidal with 5-membership function and the values of $\mathrm{R}^{2}$, RMSE and COV for the trapezoidal with 4-membership function are 0.99978, 0.02424 and 1.68948, respectively, for thermal efficiency. However, the current, power and thermal efficiency predicted by the trapezoidal with 2- and 3-membership functions show the errors above $\pm 15 \%$ from the experimental which are not within permissible limit.

The comparison of experimental and ANFIS predicted results of the current, power and thermal efficiency of the thermoelectric generator system for waste heat recovery using a gbell membership function is shown in Figure 10c. The prediction accuracy of the gbell with a 4-membership function for the current of the thermoelectric generator system for waste heat recovery shows the best and decreases with 5-, 3- and 2-membership functions. The values of $\mathrm{R}^{2}$, RMSE and COV for gbell with 4-membership function are $0.99998,0.02266$ and 0.51393 , respectively, for the current. For the power and thermal efficiency of the thermoelectric generator system for waste heat recovery, the gbell with 3-membership function shows a better agreement than gbell with 5- and 4-membership functions. The values of $\mathrm{R}^{2}$, RMSE and COV for gbell with 3-membership function are 0.99996, 0.04812 and 0.69281, respectively, for the power but $0.99994,0.01241$ and 0.86506 , respectively for the thermal efficiency. However, the prediction accuracy of the power and thermal efficiency of the thermoelectric generator system for waste heat recovery using gbell with a 2-membership function show the errors above $\pm 15 \%$ from the corresponding experimental which are not the permissible limit.

The comparison of experimental and ANFIS predicted results of the current, power and thermal efficiency of the thermoelectric generator system for waste heat recovery using a gauss membership function is shown in Figure 10d. For the current, power and thermal efficiency of the thermoelectric generator system for waste heat recovery, the prediction accuracy of the gauss with a 5-membership function shows the best and decreases with 4-, 3- and 2-membership functions. The values of $\mathrm{R}^{2}$, RMSE and COV for the gauss with 5-membership function are 0.99998, 0.02165 and 0.49110 , respectively for the current, $0.99997,0.04429$ and 0.63770, respectively, for the power and 0.99997, 0.00911 and 0.63516, respectively, for the thermal efficiency. However, the current, power and thermal efficiency of the thermoelectric generator system for waste heat recovery using gauss with 2-membership function show the errors above $\pm 15 \%$ from the corresponding experimental which are not a permissible limit.

The comparison of experimental and ANFIS predicted results of the current, power and thermal efficiency of the thermoelectric generator system for waste heat recovery using a gauss 2-membership 
function is shown in Figure 10e. For the current and thermal efficiency of the thermoelectric generator system for waste heat recovery, the gauss 2 with 4-membership function shows higher prediction accuracy than gauss 2 with a 5-membership function, but the gauss 2 with 5-membership function shows higher prediction accuracy than gauss2 with 4-membership function for the power. The values of $R^{2}$, RMSE and COV for the gauss2 with 4-membership function are 0.99998, 0.02377 and 0.53902 , respectively, for the current and 0.99992, 0.01437 and 1.0012, respectively, for the thermal efficiency. In addition, the values of $\mathrm{R}^{2}$, RMSE and COV for gauss 2 with a 5-membership function are $0.99992,0.06965$ and 1.00285 , respectively, for the power. However, the current, power and thermal efficiency of the thermoelectric generator system for waste heat recovery using gauss 2 with 2- and 3 -membership function show the errors above $\pm 15 \%$ from the corresponding experimental which are not the permissible limit.

The comparison of experimental and ANFIS predicted results of current, power and thermal efficiency of the thermoelectric generator system for waste heat recovery using a pi membership function is shown in Figure 10f. For the current, power and thermal efficiency of the thermoelectric generator system for waste heat recovery, the pi with 5-membership function shows higher prediction accuracy than pi with a 4-membership function. The values of $\mathrm{R}^{2}$, RMSE and COV for pi with a 5-membership function are 0.99998, 0.02469 and 0.55991, respectively, for the current, 0.99997, 0.04029, and 0.58006 , respectively, for the power and $0.99997,0.00931$, and 0.64890 , respectively, for the thermal efficiency. However, the current, power and thermal efficiency of the thermoelectric generator system for waste heat recovery using pi with 2 and 3-membership functions show the errors above $\pm 15 \%$ from the corresponding experimental which are not a permissible limit.

The comparison of experimental and ANFIS predicted results of current, power and thermal efficiency of the thermoelectric generator system for waste heat recovery using a dsig membership function is shown in Figure 10g. For the current of the thermoelectric generator system for waste heat recovery, dsig with a 4-membership function shows higher prediction accuracy than dsig with a 5-membership function. In addition, for the power and thermal efficiency of the thermoelectric generator system for waste heat recovery, dsig with a 5-membership function shows higher prediction accuracy than dsig with 4-membership function. The values of $\mathrm{R}^{2}$, RMSE and COV for dsig with a 4-membership function are $0.99998,0.02360$ and 0.53534 , respectively, for the current. In addition, the values of $\mathrm{R}^{2}$, RMSE and COV for dsig with a 5-membership function are 0.99990, 0.07853 and 1.13067, respectively, for the power and $0.99989,0.01704$ and 1.18732, respectively, for the thermal efficiency. However, the current, power and thermal efficiency of the thermoelectric generator system for waste heat recovery using dsig with 2 and 3-membership functions show the errors above $\pm 15 \%$ from the corresponding experimental, which are not a permissible limit.

The same number of the membership functions results in almost the same prediction cost. As the number of the membership functions increases, it results in a higher prediction cost. When the prediction accuracy plays a crucial role, the ANFIS model with a pi-5-membership function or a gauss-5-membership function could be recommended to predict the current, power and thermal efficiency of the thermoelectric generator system for waste heat recovery [40]. The prediction accuracy of the ANFIS model for the current, power and thermal efficiency is shown in Table 4a for pi membership function and Table $4 \mathrm{~b}$ for gauss membership function, respectively. When the prediction cost plays a crucial role, the ANFIS model with gbell-3-membership function could be suggested to predict the current, power and thermal efficiency of the thermoelectric generator system for waste heat recovery as shown in Table $4 \mathrm{c}$. Table $4 \mathrm{c}$ shows the prediction accuracy of an ANFIS model with a gbell membership function for the current, power and thermal efficiency of the thermoelectric generator system for waste heat recovery. The proposed ANFIS model with pi- 5 or gauss- 5 and gbell- 3 show better prediction accuracy than the coupled numerical approach for the current, power and thermal efficiency of the thermoelectric generator system for waste heat recovery [41]. 

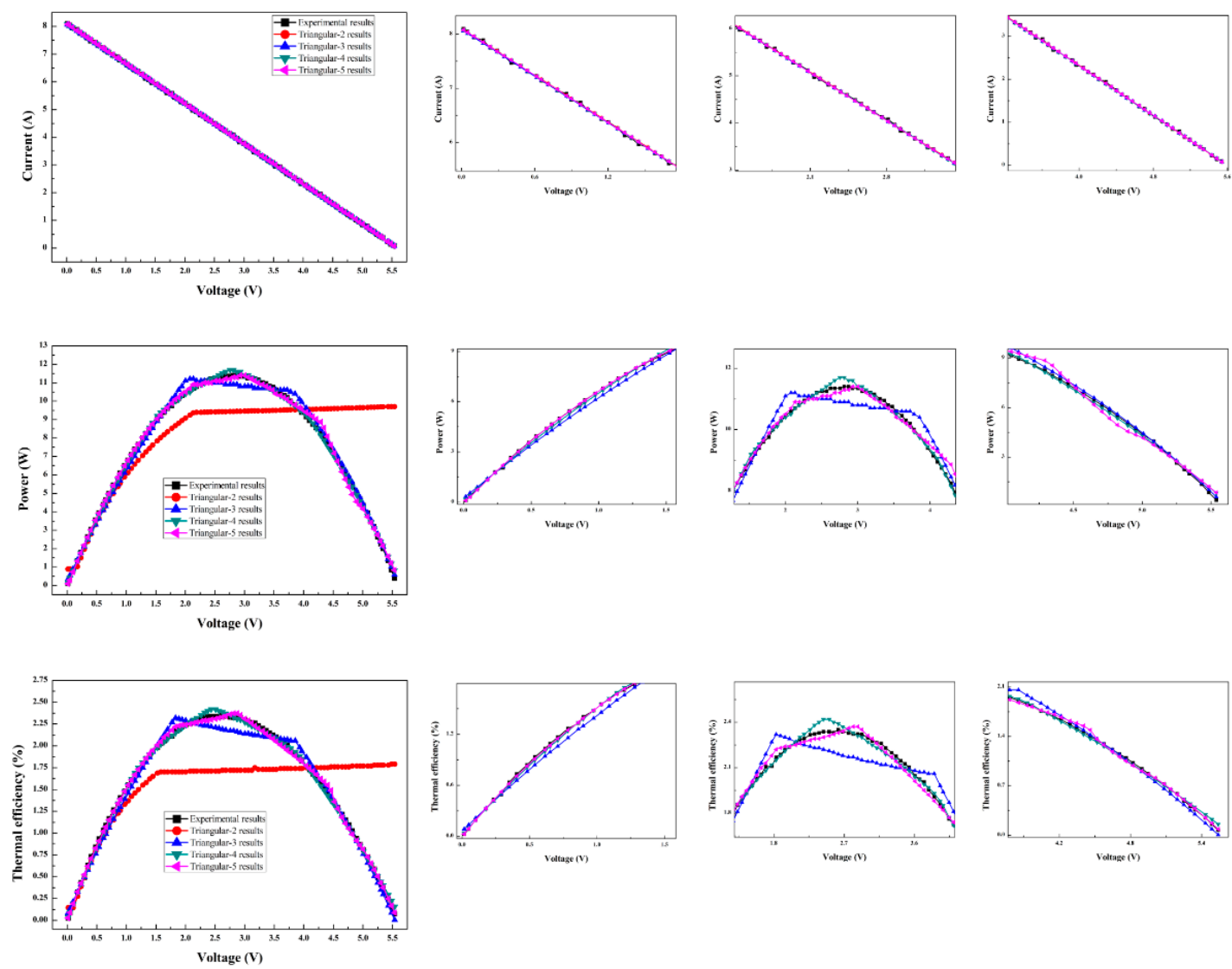

(a)

Figure 10. Cont. 

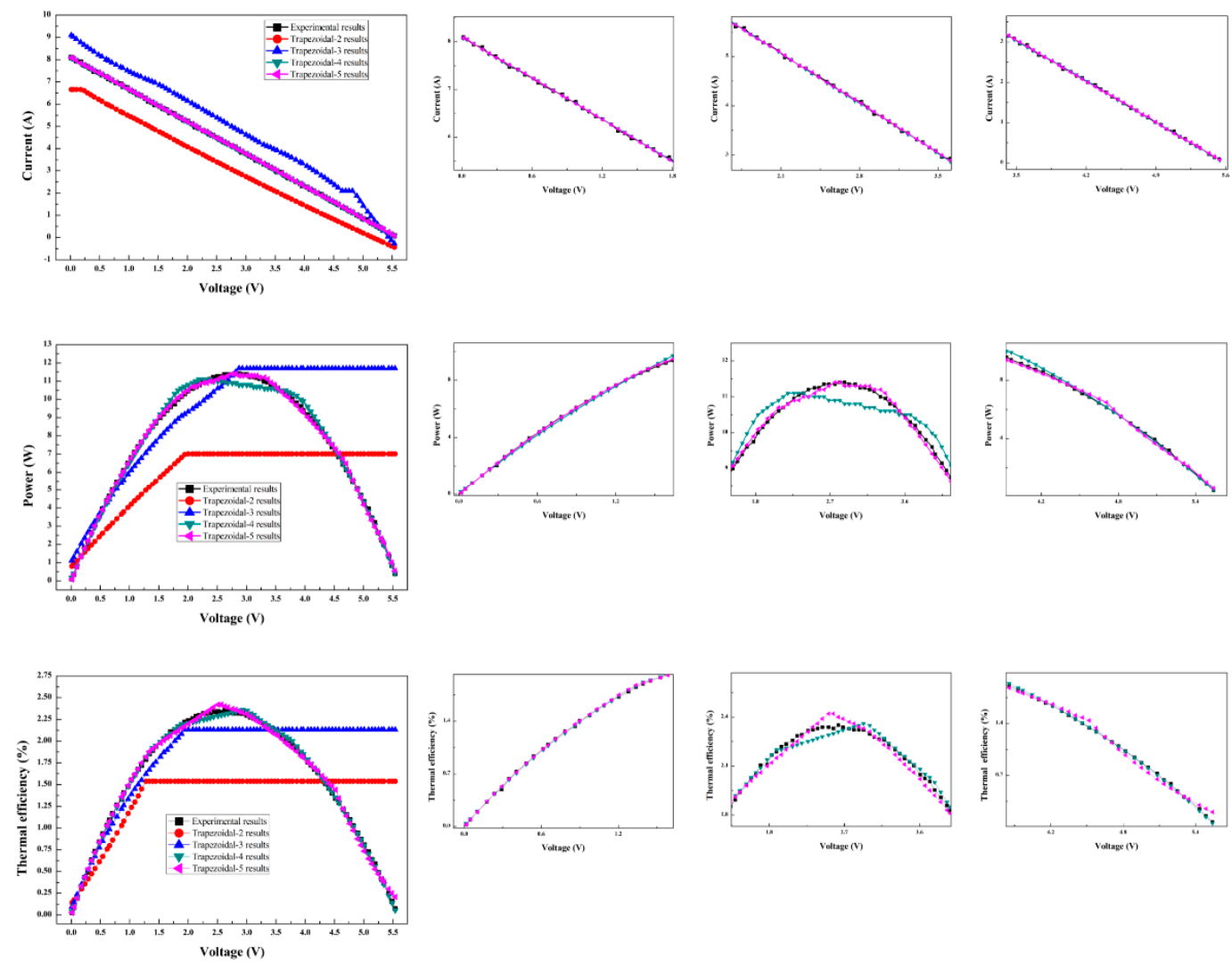

(b)
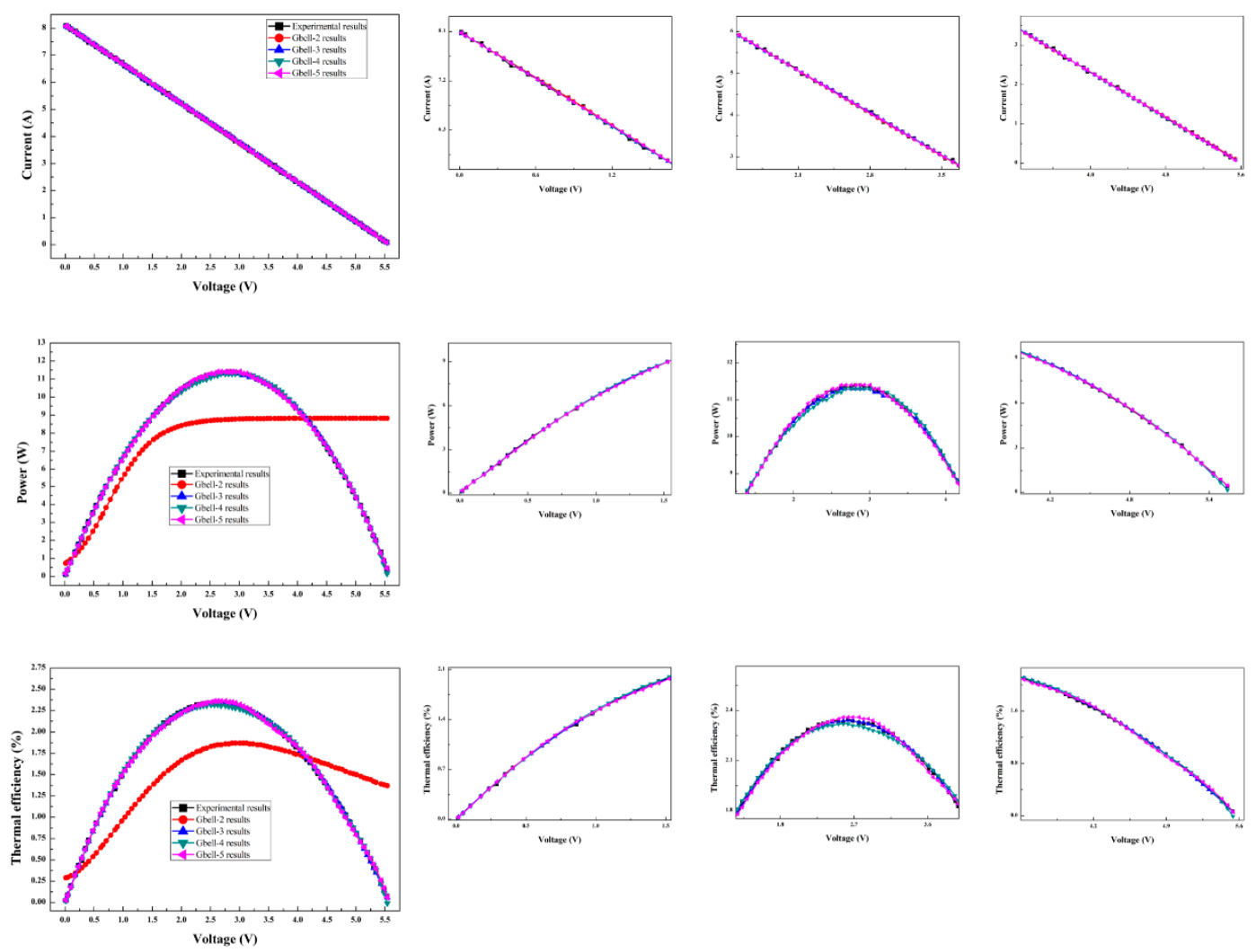

(c)

Figure 10. Cont. 

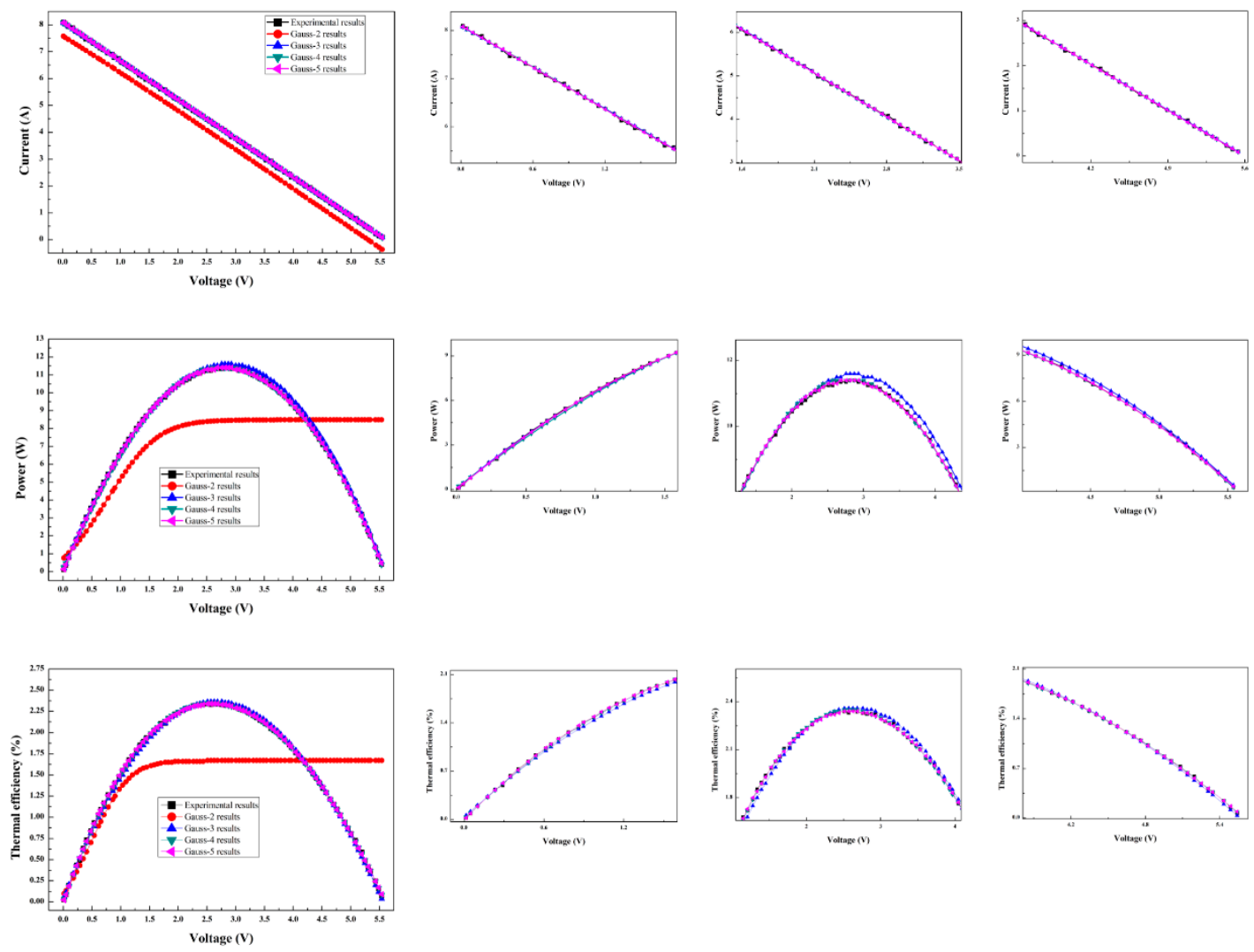

(d)

Figure 10. Cont. 

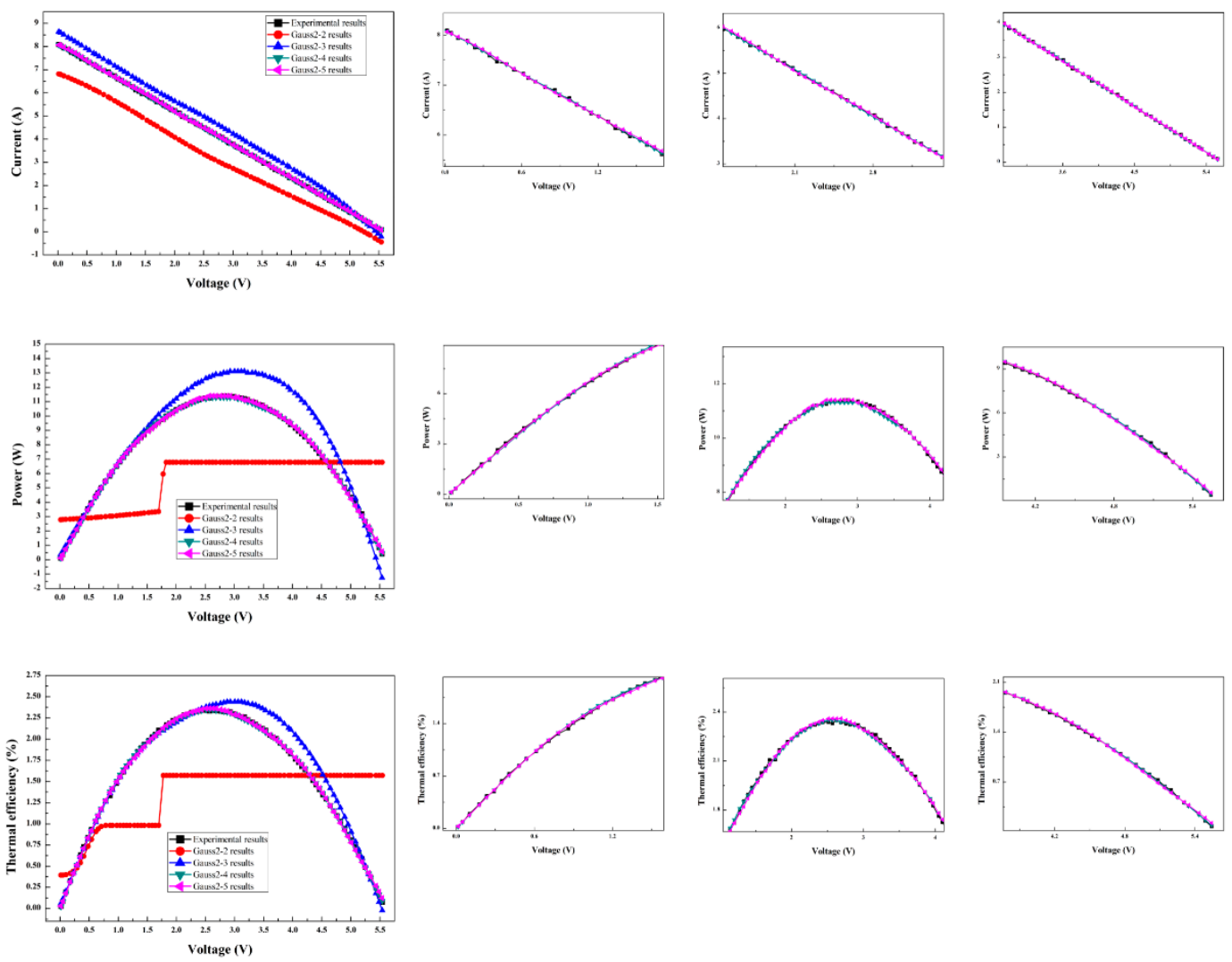

(e)
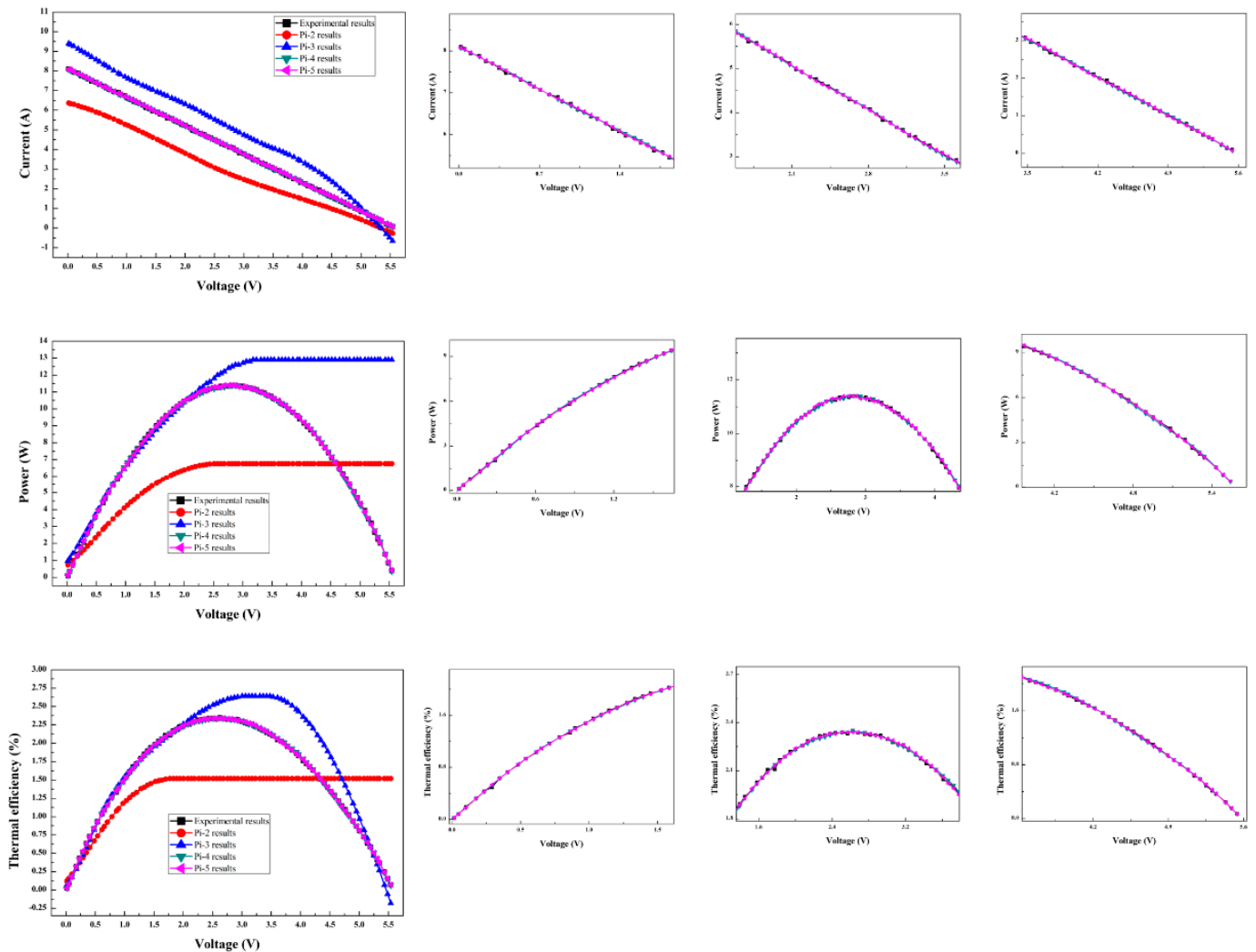

(f)

Figure 10. Cont. 

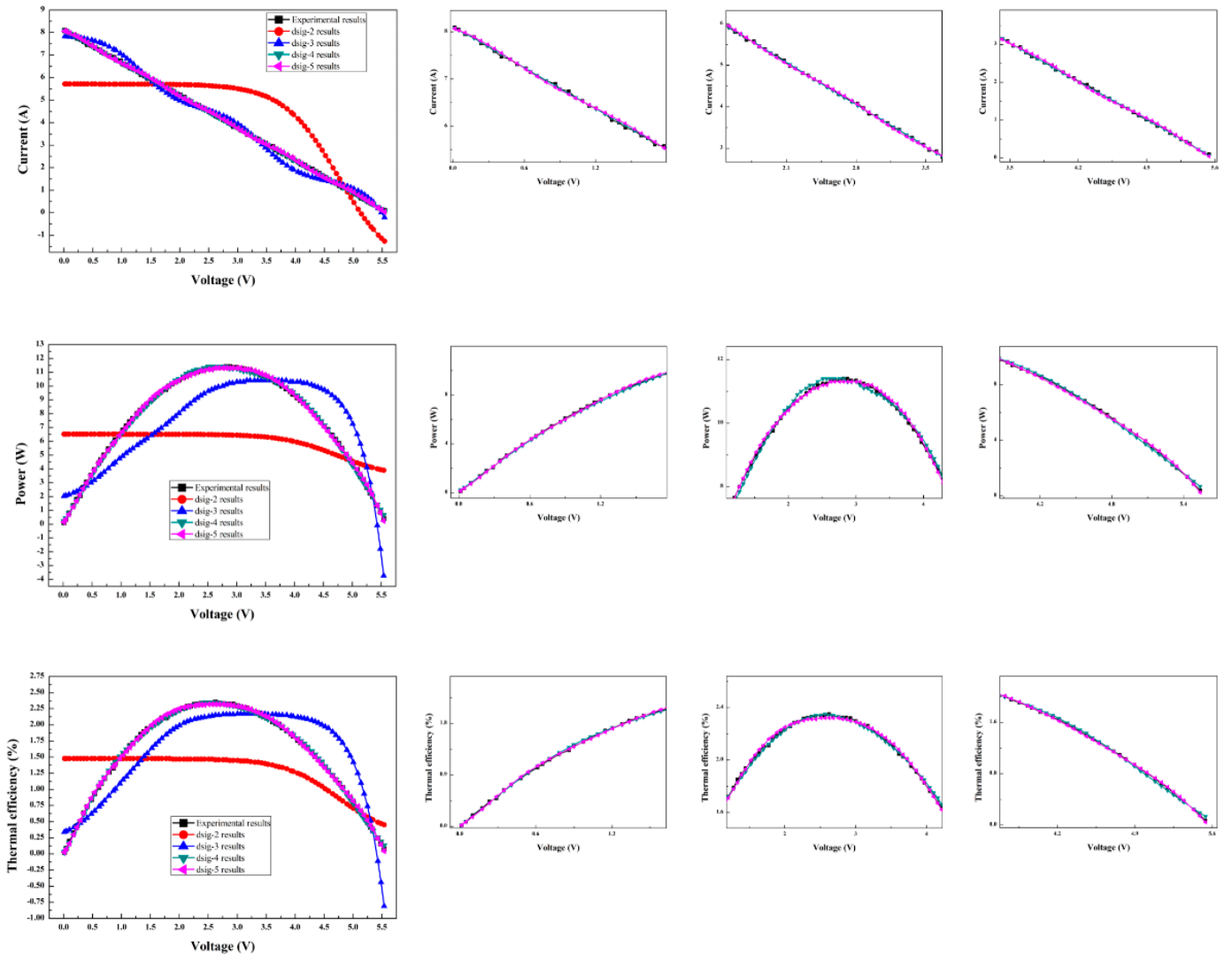

(g)

Figure 10. The comparison of experimental and ANFIS predicted results of current, power and thermal efficiency for (a) triangular membership function, (b) trapezoidal membership function, (c) gbell membership function, (d) gauss membership function, (e) gauss2-membership function, (f) pi membership function, and (g) dsig membership function.

Table 4. (a) The prediction accuracy of ANFIS model with pi membership function for current, power and thermal efficiency; (b) The prediction accuracy of ANFIS model with a gauss membership function for current, power and thermal efficiency; (c) The prediction accuracy of ANFIS model with a gbell membership function for current, power and thermal efficiency.

(a)

\begin{tabular}{ccccc}
\hline Parameter & Number of Membership Functions & $\mathbf{R}^{\mathbf{2}}$ & RMSE & COV \\
\hline Current & 2 & 0.94053 & 1.23658 & 28.0468 \\
& 3 & 0.96078 & 1.00416 & 22.7752 \\
& 4 & 0.99997 & 0.02852 & 0.64682 \\
Power & 5 & 0.99998 & 0.02469 & 0.55991 \\
& 2 & 0.83830 & 3.19468 & 45.9964 \\
& 3 & 0.71781 & 4.22023 & 60.7620 \\
\multirow{3}{*}{ Thermal efficiency } & 4 & 0.99994 & 0.05948 & 0.85635 \\
& 5 & 0.99997 & 0.04029 & 0.58006 \\
& 2 & 0.87063 & 0.58791 & 41.1021 \\
& 3 & 0.96815 & 0.29262 & 20.3952 \\
& 4 & 0.99994 & 0.01257 & 0.87619 \\
& 5 & 0.99997 & 0.00931 & 0.64890 \\
\hline
\end{tabular}


Table 4. Cont.

(b)

\begin{tabular}{ccccc}
\hline Parameter & Number of Membership Functions & $\mathbf{R}^{\mathbf{2}}$ & RMSE & COV \\
\hline Current & 2 & 0.99250 & 0.43925 & 9.96247 \\
& 3 & 0.99998 & 0.02366 & 0.53671 \\
& 4 & 0.99998 & 0.02254 & 0.51116 \\
Power & 5 & 0.99998 & 0.02165 & 0.49110 \\
& 2 & 0.88660 & 2.67538 & 38.5195 \\
& 3 & 0.99957 & 0.16457 & 2.36942 \\
Thermal efficiency & 4 & 0.99988 & 0.08667 & 1.24784 \\
& 5 & 0.99997 & 0.04429 & 0.63770 \\
& 2 & 0.88430 & 0.55769 & 38.8710 \\
& 3 & 0.99967 & 0.03002 & 2.09204 \\
& 4 & 0.99996 & 0.01056 & 0.73603 \\
& 5 & 0.99997 & 0.00911 & 0.63516 \\
\hline
\end{tabular}

(c)

\begin{tabular}{ccccc}
\hline Parameter & Number of Membership Functions & $\mathbf{R}^{\mathbf{2}}$ & RMSE & COV \\
\hline Current & 2 & 0.99997 & 0.02820 & 0.63965 \\
& 3 & 0.99998 & 0.02432 & 0.55166 \\
& 4 & 0.99998 & 0.02266 & 0.51393 \\
Power & 5 & 0.99998 & 0.02325 & 0.52728 \\
& 2 & 0.88847 & 2.65317 & 38.1999 \\
& 3 & 0.99996 & 0.04812 & 0.69281 \\
Thermal efficiency & 4 & 0.99990 & 0.08003 & 1.15220 \\
& 5 & 0.99996 & 0.04865 & 0.70043 \\
& 2 & 0.90510 & 0.50507 & 35.2033 \\
& 3 & 0.99994 & 0.01241 & 0.86506 \\
& 4 & 0.99984 & 0.02086 & 1.45405 \\
& 5 & 0.99987 & 0.01848 & 1.28804 \\
\hline
\end{tabular}

Additionally, the developed ANN and ANFIS models could accurately predict the performances like the current, power and thermal efficiency of the thermoelectric generator system for waste heat recovery with less computational time and cost because the experimental and coupled numerical approaches could be expensive and time consuming. Therefore, the proposed methodology to develop the ANN and ANFIS models could be applicable to accurately predict the performances of the various physical systems like solar based systems, refrigeration systems, heat exchanger systems, thermoelectric coolers, etc.

\section{Conclusions}

The coupled numerical approach is investigated to predict the current, power and thermal efficiency of the thermoelectric generator system for waste heat recovery. Six ANN and seven ANFIS models are developed to predict the current, power and thermal efficiency of the thermoelectric generator system for waste heat recovery using the hot gas inlet temperatures and the voltage conditions as the inputs. Six ANN models with combinations of three training variants of Levenberg-Marquardt (LM), Scaled Conjugate Gradient (SCG) and Pola-Ribiere Conjugate Gradient (CGP), two transfer functions of Tan-Sigmodal and Log-Sigmoidal and the number of hidden neurons of 10, 15, 20 and 25 are compared. Seven ANFIS models are compared with seven types of the membership functions of triangular, trapezoidal, gauss, gauss2, gbell, pi and dsig, and the number of the membership functions of 2, 3, 4 and 5. The optimum ANN and ANFIS models are proposed from the comparison with experimental data using three statistical parameters of the coefficient of determination $\left(R^{2}\right)$, root mean square error (RMSE) and coefficient of variance (COV). The ANN model with back-propagation algorithm, Levenberg-Marquardt training variant, Tan-Sigmoidal transfer function, and 25 hidden 
neurons is suggested as the optimum model based on optimum values of statistical parameters for the prediction of the current, power and thermal efficiency of the thermoelectric generator system for waste heat recovery. The ANFIS model with gbell membership function in a number of sets of 3 is suggested as the optimum model based on optimum values of statistical parameters to predict the current, power and thermal efficiency of the thermoelectric generator system for waste heat recovery with low prediction cost and acceptable prediction accuracy. The ANFIS model with pi or gauss membership function in the number of sets of 5 is suggested as the optimum model based on optimum values of statistical parameters to predict the current, power and thermal efficiency of the thermoelectric generator system for waste heat recovery with higher prediction accuracy. The optimum ANN and ANFIS models show better prediction of the current, power and thermal efficiency of the thermoelectric generator system for waste heat recovery with low computational time and cost than the coupled numerical approach.

Author Contributions: Conceptualization, K.S.G.; J.-H.S., and M.-Y.L.; methodology, K.S.G.; J.-H.S.; C.-P.C., and M.-Y.L.; software, K.S.G. and J.-H.S.; validation, K.S.G. and J.-H.S.; formal analysis, K.S.G.; J.-H.S.; C.-P.C., and M.-Y.L.; investigation, K.S.G.; J.-H.S.; C.-P.C., and M.-Y.L.; resources, K.S.G. and J.-H.S.; data curation, K.S.G.; writing —original draft preparation, K.S.G.; J.-H.S. and M.-Y.L.; writing—review and editing, K.S.G.; J.-H.S. and M.-Y.L.; visualization, K.S.G.; supervision, M.-Y.L.; project administration, M.-Y.L.; funding acquisition, M.-Y.L. All authors have read and agreed to the published version of the manuscript.

Funding: This research received no external funding.

Acknowledgments: This work was supported by the Dong-A University research fund.

Conflicts of Interest: The authors declare no conflict of interest.

\section{References}

1. Demirel, Y. Energy: Production, Conversion, Storage, Conservation, and Coupling; Springer Science \& Business Media: Berlin/Heidelberg, Germany, 2012.

2. Riffat, S.B.; Ma, X. Thermoelectrics: A review of present and potential applications. Appl. Therm. Eng. 2003, 23, 913-935. [CrossRef]

3. Wang, Y.; Li, S.; Xie, X.; Deng, Y.; Liu, X.; Su, C. Performance evaluation of an automotive thermoelectric generator with inserted fins or dimpled-surface hot heat exchanger. Appl. Energy 2018, 218, 391-401. [CrossRef]

4. Niu, Z.; Diao, H.; Yu, S.; Jiao, K.; Du, Q.; Shu, G. Investigation and design optimization of exhaust-based thermoelectric generator system for internal combustion engine. Energy Convers. Manag. 2014, 85, 85-101. [CrossRef]

5. Liu, X.; Deng, Y.D.; Zhang, K.; Xu, M.; Xu, Y.; Su, C.Q. Experiments and simulations on heat exchangers in thermoelectric generator for automotive application. Appl. Therm. Eng. 2014, 71, 364-370. [CrossRef]

6. Quan, R.; Liu, G.; Wang, C.; Zhou, W.; Huang, L.; Deng, Y. Performance investigation of an exhaust thermoelectric generator for military SUV application. Coatings 2018, 8, 45. [CrossRef]

7. Luo, D.; Wang, R.; Yu, W.; Sun, Z.; Meng, X. Modelling and simulation study of a converging thermoelectric generator for engine waste heat recovery. Appl. Therm. Eng. 2019, 153, 837-847. [CrossRef]

8. Nithyanandam, K.; Mahajan, R.L. Evaluation of metal foam based thermoelectric generators for automobile waste heat recovery. Int. J. Heat Mass Transf. 2018, 122, 877-883. [CrossRef]

9. Cao, Q.; Luan, W.; Wang, T. Performance enhancement of heat pipes assisted thermoelectric generator for automobile exhaust heat recovery. Appl. Therm. Eng. 2018, 130, 1472-1479. [CrossRef]

10. He, W.; Wang, S. Performance Comparison of Different Exhaust Exchanger Types Considering Peak Net Power and Optimal Dimension in a Thermoelectric Generator System. Adv. Theory Simul. 2018, 1, 1800012. [CrossRef]

11. Lu, X.; Yu, X.; Qu, Z.; Wang, Q.; Ma, T. Experimental investigation on thermoelectric generator with non-uniform hot-side heat exchanger for waste heat recovery. Energy Convers. Manag. 2017, 150, 403-414. [CrossRef]

12. Rana, S.; Date, A.; Iqbal, A.; Akbarzadeh, A. Optimization model for power generation using thermoelectric generator. Energy Procedia 2019, 160, 723-730. [CrossRef] 
13. Suter, C.; Jovanovic, Z.R.; Steinfeld, A. A 1 kWe thermoelectric stack for geothermal power generationModeling and geometrical optimization. Appl. Energy 2012, 99, 379-385. [CrossRef]

14. Zhao, Y.; Wang, S.; Ge, M.; Liang, Z.; Liang, Y.; Li, Y. Performance analysis of automobile exhaust thermoelectric generator system with media fluid. Energy Convers. Manag. 2018, 171, 427-437. [CrossRef]

15. Zhao, Y.; Wang, S.; Ge, M.; Liang, Z.; Liang, Y.; Li, Y. Performance investigation of an intermediate fluid thermoelectric generator for automobile exhaust waste heat recovery. Appl. Energy 2019, 239, 425-433. [CrossRef]

16. Lu, H.; Wu, T.; Bai, S.; Xu, K.; Huang, Y.; Gao, W.; Chen, L. Experiment on thermal uniformity and pressure drop of exhaust heat exchanger for automotive thermoelectric generator. Energy 2013, 54, 372-377. [CrossRef]

17. Dheenamma, M.; Soman, D.P.; Muthamizhi, K.; Kalaichelvi, P. In pursuit of the best artificial neural network configuration for the prediction of output parameters of corrugated plate heat exchanger. Fuel 2019, 239, 461-470. [CrossRef]

18. Angeline, A.A. Power generation from combusted "Syngas" using hybrid thermoelectric generator and forecasting the performance with ANN technique. J. Therm. Eng. 2018, 4, 2149-2168. [CrossRef]

19. Angeline, A.A.; Asirvatham, L.G.; Hemanth, D.J.; Jayakumar, J.; Wongwises, S. Performance prediction of hybrid thermoelectric generator with high accuracy using artificial neural networks. Sustain. Energy Technol. Assess. 2019, 33, 53-60. [CrossRef]

20. Liu, X.; Deng, Y.D.; Li, Z.; Su, C.Q. Performance analysis of a waste heat recovery thermoelectric generation system for automotive application. Energy Convers. Manag. 2015, 90, 121-127. [CrossRef]

21. Raj, A.K.; Kunal, G.; Srinivas, M.; Jayaraj, S. Performance analysis of a double-pass solar air heater system with asymmetric channel flow passages. J. Therm. Anal. Calorim. 2019, 136, 21-38. [CrossRef]

22. Park, S.H.; Jin, Y.; Cha, J.; Hong, K.; Kim, Y.; Yoon, H.; Chung, I. High-Power-Density Skutterudite-Based Thermoelectric Modules with Ultralow Contact Resistivity Using Fe-Ni Metallization Layers. ACS Appl. Energy Mater. 2018, 1, 1603-1611. [CrossRef]

23. Seo, J.H.; Patil, M.S.; Cho, C.P.; Lee, M.Y. Heat transfer characteristics of the integrated heating system for cabin and battery of an electric vehicle under cold weather conditions. Int. J. Heat Mass Transf. 2018, 117, 80-94. [CrossRef]

24. Ma, Q.; Fang, H.; Zhang, M. Theoretical analysis and design optimization of thermoelectric generator. Appl. Therm. Eng. 2017, 127, 758-764. [CrossRef]

25. Yazdani-Chamzini, A.; Zavadskas, E.K.; Antucheviciene, J.; Bausys, R. A model for shovel capital cost estimation, using a hybrid model of multivariate regression and neural networks. Symmetry 2017, 9, 298. [CrossRef]

26. Mohanraj, M.; Jayaraj, S.; Muraleedharan, C. Performance prediction of a direct expansion solar assisted heat pump using artificial neural networks. Appl. Energy 2009, 86, 1442-1449. [CrossRef]

27. Islam, K.T.; Raj, R.G.; Mujtaba, G. Recognition of traffic sign based on bag-of-words and artificial neural network. Symmetry 2017, 9, 138. [CrossRef]

28. Moya-Rico, J.D.; Molina, A.E.; Belmonte, J.F.; Tendero, J.C.; Almendros-Ibanez, J.A. Characterization of a triple concentric-tube heat exchanger with corrugated tubes using Artificial Neural Networks (ANN). Appl. Therm. Eng. 2019, 147, 1036-1046. [CrossRef]

29. Ullah, I.; Fayaz, M.; Kim, D. Improving accuracy of the kalman filter algorithm in dynamic conditions using ANN-based learning module. Symmetry 2019, 11, 94. [CrossRef]

30. Şahin, A.Ş. Performance analysis of single-stage refrigeration system with internal heat exchanger using neural network and neuro-fuzzy. Renew. Energy 2011, 36, 2747-2752. [CrossRef]

31. Bogiatzis, A.; Papadopoulos, B. Global Image Thresholding Adaptive Neuro-Fuzzy Inference System Trained with Fuzzy Inclusion and Entropy Measures. Symmetry 2019, 11, 286. [CrossRef]

32. Liu, Y.; Wang, Q.; Zhang, X.; Song, S.; Niu, C.; Shangguan, Y. Using ANFIS and BPNN Methods to Predict the Unfrozen Water Content of Saline Soil in Western Jilin, China. Symmetry 2019, 11, 16. [CrossRef]

33. Mehrabi, M.; Pesteei, S.M. Modeling of heat transfer and fluid flow characteristics of helicoidal double-pipe heat exchangers using adaptive neuro-fuzzy inference system (ANFIS). Int. Commun. Heat Mass Transf. 2011, 38, 525-532. [CrossRef]

34. Sarkar, M.; Julai, S.; Wen Tong, C.; Toha, S.F. Effectiveness of Nature-Inspired Algorithms using ANFIS for Blade Design Optimization and Wind Turbine Efficiency. Symmetry 2019, 11, 456. [CrossRef] 
35. Yeom, C.U.; Kwak, K.C. Performance Comparison of ANFIS Models by Input Space Partitioning Methods. Symmetry 2018, 10, 700. [CrossRef]

36. Erturun, U.; Mossi, K. A feasibility investigation on improving structural integrity of thermoelectric modules with varying geometry. In Proceedings of the ASME 2012 Conference on Smart Materials, Adaptive Structures and Intelligent Systems, Stone Mountain, GA, USA, 19-21 September 2012; pp. 939-945.

37. Phillips, S.S. Characterizing the Thermal Efficiency of Thermoelectric Modules. Ph.D. Thesis, Massachusetts Institute of Technology, Cambridge, MA, USA, 2009.

38. Gunasekar, N.; Mohanraj, M.; Velmurugan, V. Artificial neural network modeling of a photovoltaic-thermal evaporator of solar assisted heat pumps. Energy 2015, 93, 908-922. [CrossRef]

39. Esen, H.; Inalli, M. ANN and ANFIS models for performance evaluation of a vertical ground source heat pump system. Expert Syst. Appl. 2010, 37, 8134-8147. [CrossRef]

40. Belaout, A.; Krim, F.; Mellit, A.; Talbi, B.; Arabi, A. Multiclass adaptive neuro-fuzzy classifier and feature selection techniques for photovoltaic array fault detection and classification. Renew. Energy 2018, 127, 548-558. [CrossRef]

41. Yaïci, W.; Entchev, E. Adaptive neuro-fuzzy inference system modelling for performance prediction of solar thermal energy system. Renew. Energy 2016, 86, 302-315. [CrossRef]

(C) 2020 by the authors. Licensee MDPI, Basel, Switzerland. This article is an open access article distributed under the terms and conditions of the Creative Commons Attribution (CC BY) license (http://creativecommons.org/licenses/by/4.0/). 